\title{
Impacts of Surface Drag Coefficient and Planetary Boundary Layer Schemes on the Structure and Energetics of Typhoon Megi (2010) during Intensification
}

\author{
Rochelle CORONEL \\ Atmospheric Science Laboratory, Department of Geophysics, Graduate School of Science, Tohoku University, \\ Sendai, Japan \\ Masahiro SAWADA \\ Meteorological Research Institute, Tsukuba, Japan \\ and \\ Toshiki IWASAKI \\ Atmospheric Science Laboratory, Department of Geophysics, Graduate School of Science, Tohoku University, \\ Sendai, Japan
}

(Manuscript received 4 February 2015, in final form 22 October 2015)

\begin{abstract}
The sensitivity of the simulated Typhoon Megi (2010) to frictional perturbations is studied by conducting experiments with the Deardorff planetary boundary layer parameterization. Here, we increase the surface drag by 50 $\%$ (Cd1.5) and change the scheme to Mellor-Yamada-Nakanishi-Niino Level 3 (MYNN) using the Meteorological Research Institute/Japan Meteorological Agency nonhydrostatic model. At 2-km horizontal resolution, the control run simulates deeper central pressure, and shallower maximum winds and inflow layer that are comparable to observations.

In this study, Cd1.5 and MYNN are found to introduce substantial change on Megi's low-level wind structures by disrupting the gradient-wind balance more than the control run. Increasing the surface drag reduces low-level tangential velocity and induces a stronger inflow near the surface and toward the center of the storm. This results in a narrow radius and lower height of the maximum tangential wind. On the contrary, the MYNN case increases the cyclone's size and elevates the level of the induced inflow at the boundary layer, far from the center. From the energetics point of view, the impact of the imbalance introduced by the experiments during the initial stage of intensification is dual, i.e., while it enhances the generation of kinetic energy, it also amplifies frictional dissipation. In the kinetic energy equation, the induced inflow strengthens the secondary circulation, and subsequently, intensifies the dynamical energy conversion. On the other hand, our results illustrate that the mechanism for energy loss in Cd1.5 is significantly different from that in MYNN due to their different impacts on wind structures and momentum flux. Nevertheless, the increase in energy gain in both experiments is overweighed by the loss due to large dissipation of absolute angular momentum, leaving less kinetic energy for further intensification.
\end{abstract}

Keywords tropical cyclones; energetics; nonhydrostatic model; PBL schemes; friction

Corresponding author and present affiliation: Rochelle

Coronel, Regional Climate Systems, Manila Observatory,

Ateneo de Manila University Campus, Loyola Heights,

Quezon City 1101, Philippines

E-mail: rcoronel@observatory.ph

C2016, Meteorological Society of Japan 


\section{Introduction}

Friction is known to play a dual role in the growth of a tropical cyclone (TC); it aids a TC by initiating strong inflow and low-level convergence that help transports angular momentum, water vapor and heat into the center of the cyclone (Ooyama 1964, Charney and Eliassen 1964, Rosenthal 1971). On the other hand, friction weakens a TC by dissipating kinetic energy $(K E)$, inhibiting the intensification and shrinking of the vortex. However, the impact of friction may vary depending on the initial conditions. In the presence of strong eyewall convection, for instance, friction has a positive effect as it narrows the potential vorticity (PV) annulus through stretching deformation; however, without condensational heating, surface friction dissipates PV in the eyewall (Wu et al. 2009). Fang et al. (2009) showed that if a TC is formed from a low-level vortex with a warm core, friction helps the system by accelerating the buildup of convective available potential energy; however, friction-induced dissipation offsets its positive impacts if the TC is initiated from a mesoscale convective vortex. As mentioned in these previous studies, there are many factors that determine the sensitivity of a TC to frictional forcings. Here, we deal with a realistic environment and artificially introduce frictional perturbations through planetary boundary layer (PBL) parameterizations.

Several works have studied TCs in relation to surface and PBL parameterizations (Donelan et al. 1997; Braun and Tao 2000; Nolan et al. 2009a, b; Smith and Thomsen 2010; Bell et al. 2012). Most of these studies provided insights into the sensitivity of TCs to PBL parameterizations but with distinct outcomes for different schemes. Recently, several researchers tried to address the issue of why a particular PBL scheme behaves differently from the other by focusing on the fundamental features of PBL dynamics. For instance, Kanada et al. (2012) emphasized the role of subgrid-mixing length and its associated diffusivity coefficients in the maintenance of an upright contracted eyewall of extremely strong TCs $(<904 \mathrm{hPa})$. Using the Meteorological Research Institute/Japan Meteorological Agency nonhydrostatic model (MRI/JMA NHM; Saito et al. 2007) with atmospheric general circulation model future projections, it was shown that large vertical eddy diffusivities in lower layers lead to large heat and water vapor transfers, and subsequently, strong TCs.

More recently, Gopalakrishnan et al. (2013) performed an idealized numerical experiment with the Hurricane Weather Research and Forecasting model V3.2 and showed that reducing the diffusivity coefficient for momentum $\left(\kappa_{m}\right)$ increases the frictional force, which then enhances the PBL inflow and lessens the dissipation of absolute angular momentum (AAM) in the PBL, and consequently, spins up the storm. This is contrary to the findings of Smith and Vogl (2008) where the maximum tangential wind is attained with larger vertical diffusion momentum coefficient; that is, an increase in $\kappa_{m}$, and hence, wind stress, leads to a larger disruption of the gradient-wind balance. The imbalance induces a stronger inflow in the boundary layer, which then minimizes the loss of AAM in the PBL. The "gradientwind imbalance" was further justified in a series of idealized numerical studies (Smith and Montgomery 2008; Smith and Vogl 2008; Montgomery and Smith 2011; Smith et al. 2009, 2014; Smith and Thomsen 2010) concerning $C d$. Their results challenge the assumption of a gradient-wind balance in the boundary layer under Emanuel's maximum potential intensity theory (Emanuel 1986, 1995). Bryan (2013), on the other hand, contradicted Montgomery et al. (2010) and showed that with a longer model integration time, the maximum intensity is always inversely proportional to $C d$. The goal of the current paper is to further investigate the frictional effects of surface drag and eddy wind stress to an actual TC by relating the kinetic energy budget to the cyclone's circulation. Here, PBL sensitivity experiments are performed on Typhoon Megi (2010) during its intensification over the ocean.

In the succeeding sections, the observed synoptic conditions during Typhoon Megi and the experimental design are described briefly in Section 2. It is followed by the discussions of the simulated Typhoon Megi and the impacts of the sensitivity experiments in Section 3. Finally, the summary and conclusion is presented in Section 4.

\section{Overview of Typhoon Megi and the experimental design}

\subsection{Synoptic summary of Typhoon Megi}

Typhoon Megi is one of the most intense TCs on record reaching a central pressure of $885 \mathrm{hPa}$ and a 10-min average maximum sustained wind of 64.31 $\mathrm{m} \mathrm{s}^{-1}$ (JMA Regional Specialized Meteorological Center (RSMC) best track data). It formed over the Western North Pacific Ocean at 12:00 UTC October 13 and dissipated after making landfall over Southeastern China at 18:00 UTC October 23, 2010. In this study, the numerical analysis is focused on the early 


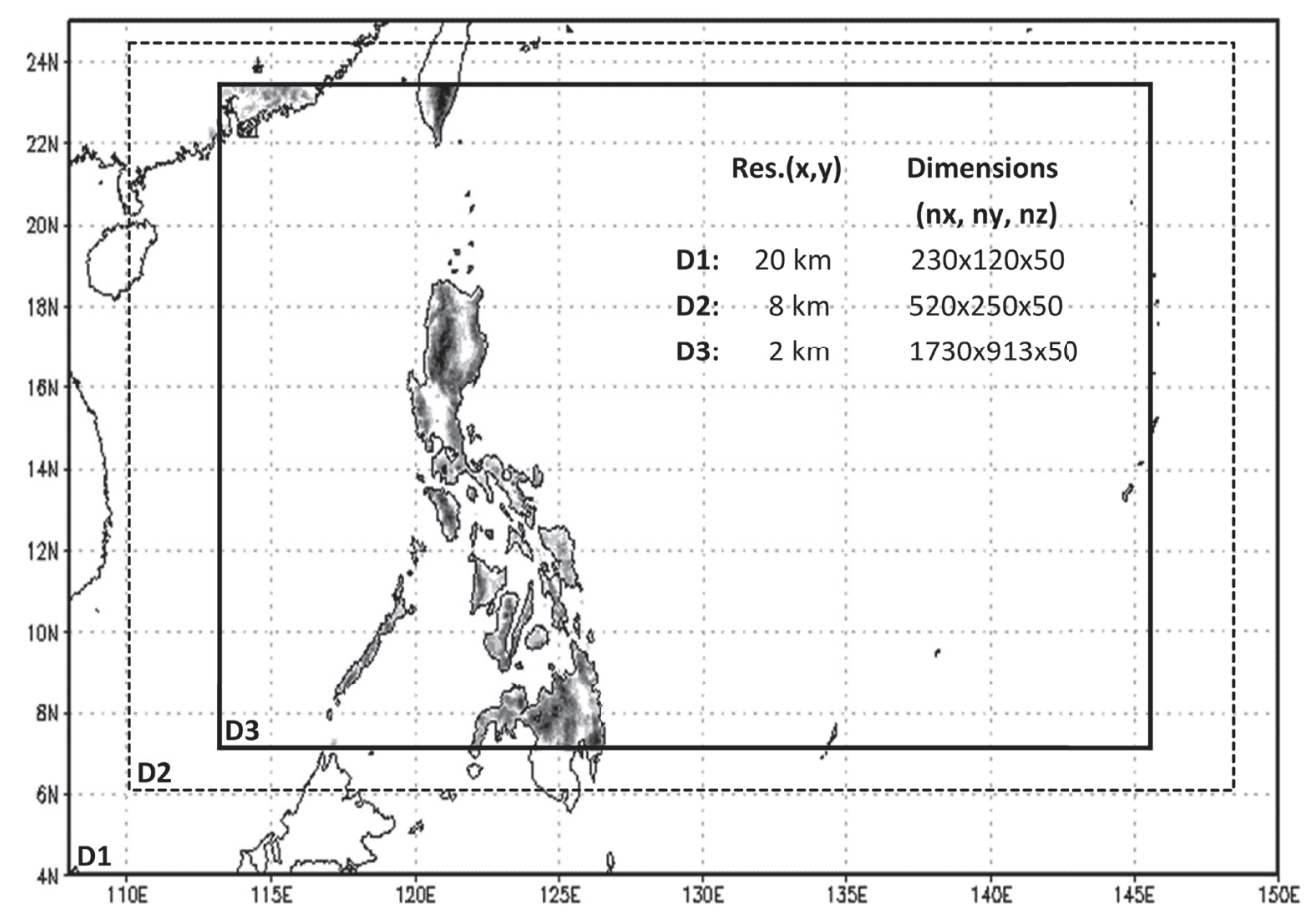

Fig. 1. Spatial coverage of the model domains. The shaded contour refers to the terrain of the innermost domain.

intensification (EI) stage of Typhoon Megi before its rapid intensification.

During the early stage of Megi, several synoptic patterns favorable for intensification were observed and analyzed by weather bureaus (e.g., JMA; Joint Typhoon Warning Center; Philippine Atmospheric, Geophysical and Astronomical Services Administration) and research institutions (e.g., Cooperative Institute for Mesoscale Meteorological Studies). Megi was observed of being steered northwestward, and then west-southwestward by the east-to-west winds of a mid-level subtropical ridge (STR) positioned north of Megi. As a short-wave trough propagated northeastward, the STR was strengthened, steering Megi in a region of very favorable upper-level winds and oceanic conditions such as weak wind shear, high SST and high oceanic energy (Wang and Wang 2014). Here, we further explore the results of model simulations to understand the dynamics of Megi's intensification.

\subsection{The model set-up}

The intensification of Typhoon Megi (2010) was investigated using the MRI/JMA nonhydrostatic model (Saito et al. 2007). Three domains (D1, D2, and D3) of 50 terrain-following vertical levels $(z)$ were prepared with 20-, 8-, and 2-km grid sizes, respectively (see details in Fig. 1 and Table 1). The model's vertical grid $(d z)$ follows a generalized hybrid coordinate system which varies from $10 \mathrm{~m}$ between the first and second levels $\left(z_{\text {bottom }}=10 \mathrm{~m} ; z_{2}=20 \mathrm{~m}\right)$, up to $d z=1097.5 \mathrm{~m}$ between $z_{49}$ and the top height $\left(z_{\text {top }}=27.32 \mathrm{~km}\right)$. The initial and boundary conditions for the first domain were obtained by processing the $1.25^{\circ} \times 1.25^{\circ}$ grid-sized Japan Reanalysis data (JRA25; Onogi et al. 2007) and the $0.25^{\circ} \times 0.25^{\circ}$ gridded Merged-satellite and in situ data Global Daily Sea Surface Temperature (Kurihara et al. 2006) into NHM-readable input data.

The innermost domain with a 2-km horizontal resolution was simulated with the Deardorff (DF) scheme as the PBL parameterization (Deardorff 1980). The mixing length was determined by the Blackadar scheme (Blackadar 1962) while the PBL height was derived from the potential temperature profile. The surface fluxes were parameterized using the Beljaars and Holtslag scheme (Beljaars and Holtslag 1991). The bulk cloud microphysics parameterization (Murakami 1990) was incorporated, where the mixing ratios of water vapor, cloud water, rainwater, cloud ice, snow, and graupel are treated as prognostic variables. Cumulus parameterization (CP) was turned off 
Table 1. The model settings for the three domains.

\begin{tabular}{|c|c|c|c|}
\hline Domain & D1 & D2 & D3 \\
\hline Model & \multicolumn{3}{|c|}{ MRI/JMA Nonhydrostatic Model } \\
\hline Horizontal mesh & $20 \mathrm{~km}$ & $8 \mathrm{~km}$ & $2 \mathrm{~km}$ \\
\hline Timestep & $30 \mathrm{~s}$ & $20 \mathrm{~s}$ & $10 \mathrm{~s}$ \\
\hline Nesting & \multicolumn{3}{|c|}{ One-way nesting } \\
\hline Integration time & Oct. $13-22$ & Oct. $13-20$ & Oct. $14-19$ \\
\hline Vertical coordinate & \multicolumn{3}{|c|}{$\begin{array}{c}\text { Generalized hybrid coordinate } \\
50 \text { levels }(d z=10 \text { to } 1096 \mathrm{~m}) ; z_{\text {bottom }}=10 \mathrm{~m}, z_{\text {top }}=27.32 \mathrm{~km}\end{array}$} \\
\hline $\begin{array}{l}\text { Boundary and Lateral } \\
\text { Conditions }\end{array}$ & $\begin{array}{l}\text { JRA25 (1.25 deg, } 6 \text { hrly); } \\
\text { MDGSST ( } 0.25 \text { deg, daily) }\end{array}$ & D1 & D2 \\
\hline Cumulus Parameterization & Kain-Fritsch CP & none & none \\
\hline PBL Parameterization & $\begin{array}{c}\text { MYNN } \\
\text { w/Partial Condensation } \\
\text { scheme }(\mathrm{PC})\end{array}$ & MYNN w/PC & $\begin{array}{c}\text { Deardorff } \\
\text { scheme w/PC }\end{array}$ \\
\hline Surface Flux & \multicolumn{3}{|c|}{ Beljaars and Holtslag scheme } \\
\hline Other Model Physics & \multicolumn{3}{|c|}{$\begin{array}{c}\text { Bulk-phase Microphysics, Blackadar mixing length, Kitagawa } \\
\text { Radiation scheme }\end{array}$} \\
\hline
\end{tabular}

to explicitly resolve cumulus clouds. The same model physics was used for the parent domains, D1 and D2, except for the Kain-Fritsch CP scheme (Kain and Fritsch 1993) applied only to the 20-km domain and MYNN PBL scheme (Nakanishi and Niino 2004) for D1 and D2.

In this study, the innermost domain D3 with Deardorff scheme is the control run (DF). Numerical experiments were conducted to investigate the impacts of frictional force by: (i) increasing the surface drag coefficient by $50 \%(\mathrm{Cd} 1.5)$; and (ii) changing the turbulent mixing scheme to Mellor-Yamada-Nakanishi-Niino Level 3 (MYNN) which have an effect on the vertical turbulent stress (eddy viscosity). Note that the Partial Condensation scheme, which is said to contribute in the improvement of the operational models of JMA after applying to MYNN (Nakanishi and Niino 2004), was also employed in the DF scheme to calculate cloud fraction and cloud water content for the radiation scheme.

\subsection{Model implementation of the DF and MYNN schemes}

In the MRI/JMA NHM, closure methods such as the DF and MYNN schemes are integrated into the model to determine the mixing coefficients (diffusivity) in relation to the turbulence kinetic energy (TKE) and mixing length $(l)$. This section briefly describes the basic difference between the DF and MYNN schemes in calculating the diffusivity coefficients for energy $\left(\kappa_{e}\right)$, momentum $\left(\kappa_{m}\right)$ and heat $\left(\kappa_{h}\right)$.

In general, the DF scheme is formulated to estimate subgrid turbulence using the eddy viscosity model and includes all terms in the TKE evolution as it models 3D and unsteady flows. It was developed for very high-resolution models where large eddies are assumed to be resolved by the model. This method was used in previous operational models of JMA before shifting to MYNN (Saito et al. 2001, 2007). MYNN, on the other hand, is an improvement of the lower-order Mellor-Yamada scheme based on a Large Eddy Simulation (LES) database (Nakanishi 2001; Nakanishi and Niino 2004, 2006).

As described in the MRI technical reports of Ikawa and Saito (1991) and Saito et al. (2001), the eddy diffusivity coefficients for the DF scheme are defined as follows:

$$
\begin{aligned}
& \kappa_{e}=2 \kappa_{m}, \\
& \kappa_{m}=C_{m} l(T K E)^{\frac{1}{2}}, \\
& \kappa_{h}=P_{r}^{-1} \kappa_{m},
\end{aligned}
$$

where $P_{r}$ is the Prandl number, and $C_{m}$ is the momentum exchange coefficient (also represent 
surface drag). In the model, $C_{m}$ was set to 0.1 in all layers.

In contrast to the DF scheme, the exchange coefficients in MYNN are formulated to vary according to LES results and certain stability functions. In particular, MYNN parameterizes turbulent eddy transfer coefficients as follows:

$$
\kappa_{e, m, h}=l(T K E) S_{e, m, h},
$$

where the subscripts $e, m$, and $h$ indicate energy, momentum and heat, respectively while $S_{e, m, h}$ is a dimensionless stability function calculated from LES data. The equations for the stability functions are defined in Section 2.2 of Nakanishi and Niino (2004). In the current study, the following LES-based closure constants were utilized:

$$
\begin{aligned}
& \left(A_{1}, A_{2}, B_{1}, B_{2}, C_{1}\right) \\
& \quad=(1.18,0.665,16.6,15.0,0.137) \\
& \left(C_{2}, C_{3}, C_{4}, C_{5}\right)=(0.7,0.323,0,0.2)
\end{aligned}
$$

where $A$ and $C$ affect pressure covariance; $B_{1}$ and $B_{2}$ are constants in the dissipation rate terms; $C_{1}, C_{4}$, and $C_{5}$ represent the effects of shear; while $C_{2}$ and $C_{3}$ symbolize buoyancy.

PBL mixing schemes are usually incorporated into numerical models to parameterize sub-grid fluxes of energy, momentum and moisture. Representation of these boundary layer eddy fluxes is important to understand the response of TCs to surface and low-level forcings. In the next chapter, the sensitivity of Typhoon Megi to our PBL parameterization experiments is presented and analyzed from the energetics point of view.

\section{Results and analysis}

\subsection{Overview of the control experiment}

To provide a general background and detailed discussion of our numerical experiments, the 2-km control run is first evaluated in relation to available observation data.

\section{a. Model verification with varying horizontal resolutions}

With the advent of high-capacity computer resources, studies on tropical cyclone simulation are now leaning towards high-resolution modeling. Recent studies suggest that, as the model resolution is increased, simulation of typhoons becomes much more realistic (Fierro et al. 2009; Gentry and Lackman 2010). As shown in Fig. 2a, the simulated intensity in terms of the central pressure approaches that of the observed value as the resolution is improved. However, the maximum intensity increases asymptotically as the resolution increases, with differences as high as $17 \mathrm{hPa}$ (between the 4- and 2-km cases) and as low as $4 \mathrm{hPa}$ (between the 2- and $1-\mathrm{km}$ cases). Although the model failed to reproduce the maximum intensity, all simulations reached their lowest pressure just before landfall (00 UTC 18 October 2010), consistent with the best track data of RSMC-Tokyo. As shown in the inset tables in Fig. 2a, the $2-\mathrm{km}$ run and the $1-\mathrm{km}$ case were able to capture rapid deepening with $1.8 \mathrm{hPa}(t=54 \mathrm{~h})$ to $2.0 \mathrm{hPa}(t$ $=48 \mathrm{~h})$ per hour, respectively. However, the intensification for the higher resolution runs was followed by a decline in the rate increased (not shown here) corresponding to the saturation of the central pressure from $t=66 \mathrm{~h}$, while the coarser $4-\mathrm{km}$ case continues to intensify. Despite the uninterrupted deepening of the 4-km run, it still failed to reach the observed rapid intensification of Megi. In terms of track, it is important to note that all simulations followed the same direction with high accuracy over the ocean (Fig. 2b). This suggests that the movement of the cyclone might be insensitive to resolutions higher than $4 \mathrm{~km}$.

While the Deardorff PBL scheme is formulated for a high-resolution model, it is still controversial as to what range of finer scales the PBL "gray zone" (Gerard 2007) is. This "gray zone" is where resolved features of the model begin to combine with the parameterized ones. In the next subsection, the accuracy of the DF scheme is compared with the MYNN PBL parameterization. MYNN is currently implemented in JMA's high-resolution Numerical Weather Prediction models (Japan Meteorological Agency 2013): Meso-scale Model (5-km resolution) and Local Forecast Model (2-km resolution). The results from the two PBL schemes are verified with dropwindsondes data from the Impact of Typhoons on the Ocean in the Pacific/Tropical Cyclone Structure 2010 (ITOP/TCS10) field experiment.

\section{b. Verification of DF and MYNN PBL schemes}

Figure 3 illustrates the wind and thermal boundary structures of Typhoon Megi at 06:00 UTC 17 October UTC in comparison with the ITOP/TCS10 data. Figure $3 \mathrm{a}$ is adapted from the presentation of Dr. Peter Black on Typhoon Megi at the 66th Interdepartmental Hurricane Conference (2012). The data are from two pairs of Global Positioning Systems dropwindsondes launched within 2 min of each other in the northeast and in the west of the storm observation quadrants as 

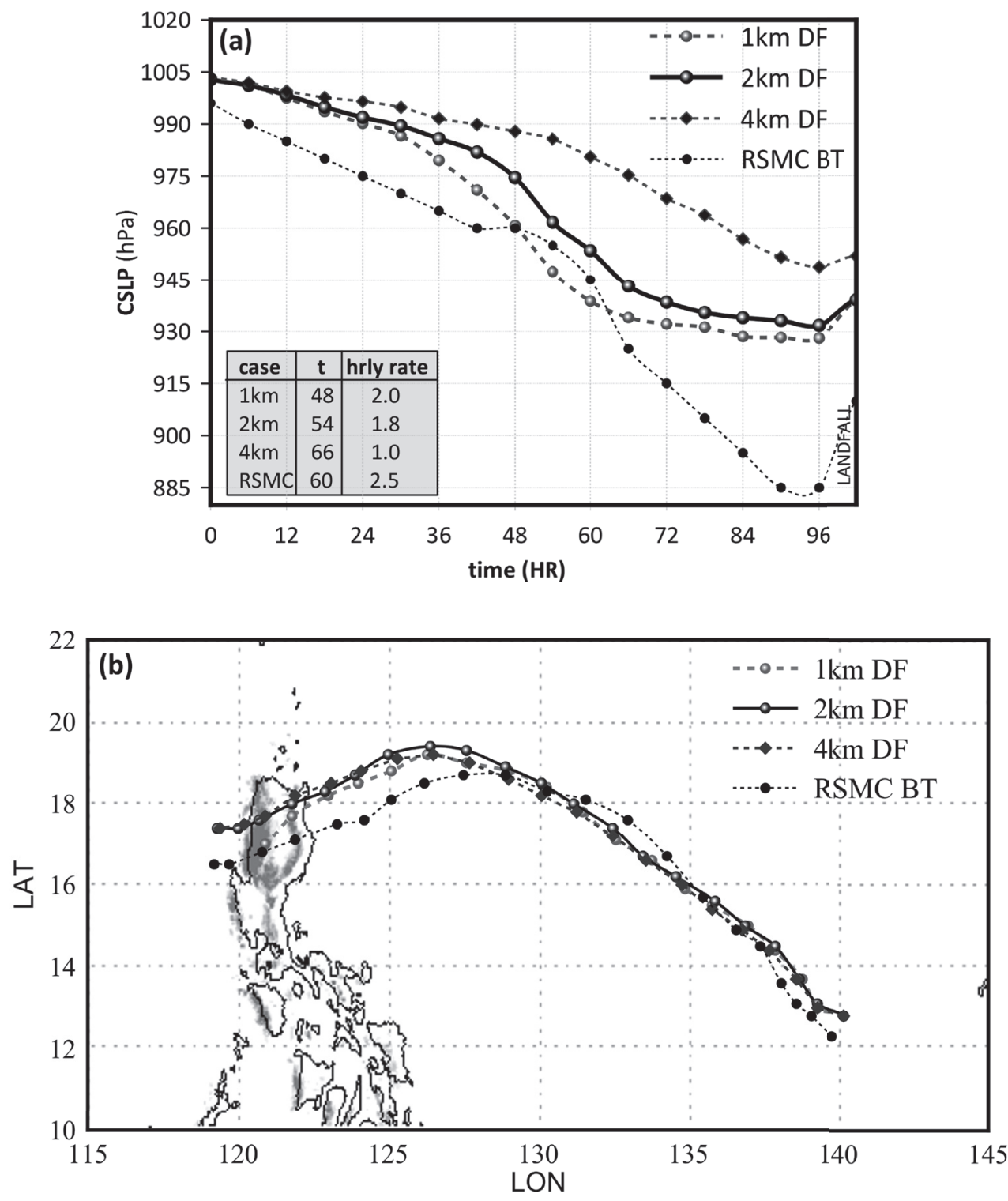

Fig. 2. The simulated 6-hourly (a) central sea level pressure (CSLP); and (b) tracks of the 2-km resolution experiment (Deardorff PBL scheme) in comparison with the observed (Regional Specialized Meteorological Center Best Track) and grid-size variations. The tracks and CSLP starts from 00:00 UTC 15 October 2010. The table inset in (a) shows the time when the rate of intensification is at its maximum.

described in Fig. 11 of Black (2012). Figure 3b, on the other hand, shows the simulated vertical structures of the eyewall after azimuthal averaging.

As shown in Fig. 3b, the DF scheme simulates a more unstable boundary layer compared to MYNN. However, the model still reproduced a weaker thermal structure in comparison to the observed structure. Additionally, the model and parameterizations needs further improvement to resolve the observed temperature peak at $z \sim 60 \mathrm{~m}$ height. The researchers from the ITOP/TCS10 project (Black 2012) hypothesized that such structure is probably due to mixing of high potential temperature air from the eye into the eyewall by micro-vortices observed within the eyewall.

Although both schemes underestimate the magnitude of wind speed of Typhoon Megi, the results 
(a) ITOP/TCS10 experiment (adapted from Black (2012)).

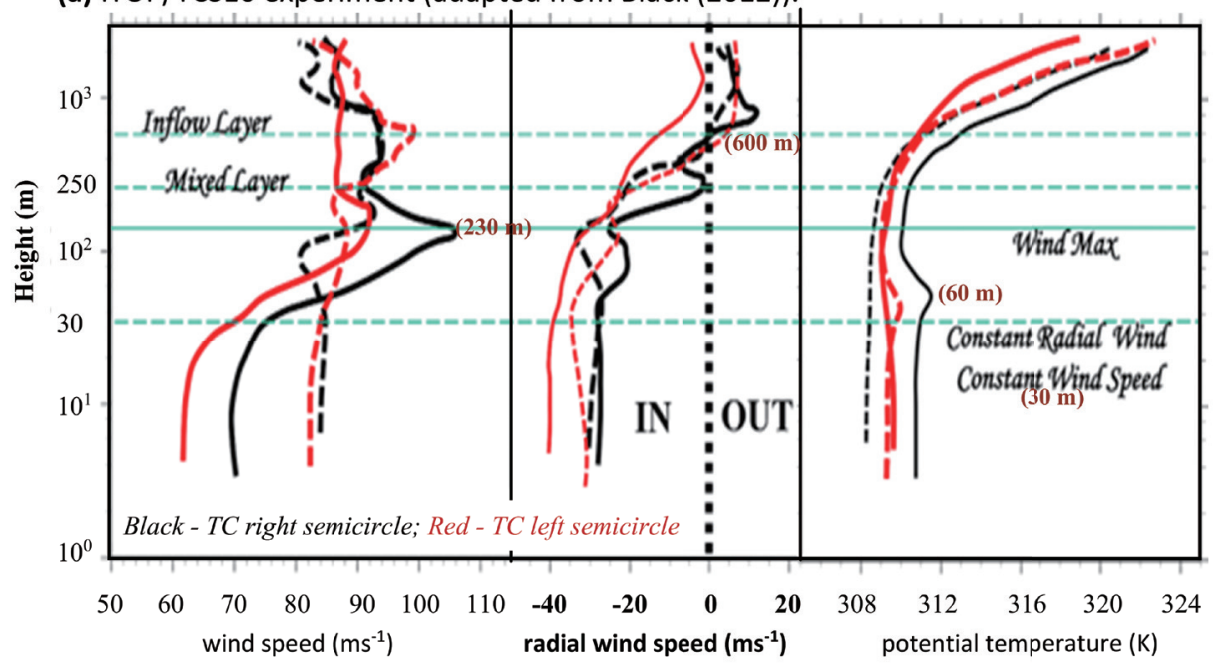

(b) Simulation results: DF vs MYNN
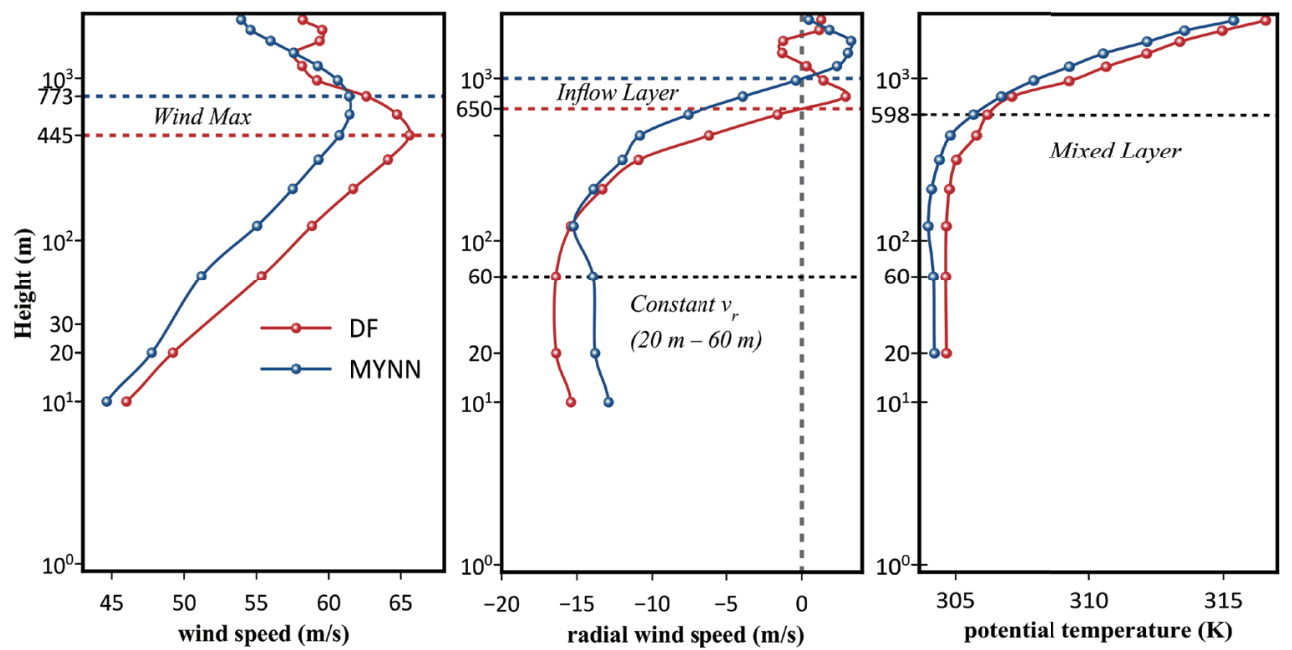

Fig. 3. Eyewall boundary layer structure of Typhoon Megi at 06:00 UTC 17 October $2010(t=78 \mathrm{~h})$ in terms tangential and radial winds, and potential temperature: (a) Measurements from the ITOP/TCS10 field experiment (Slide 9 of Black 2012); and (b) Impacts of vertical mixing schemes (DF vs MYNN).

indicate that the DF case simulates a more realistic structure than MYNN. For instance, the 230-m height observed maximum wind is found at $z=450 \mathrm{~m}$ and $773 \mathrm{~m}$ for the DF and MYNN, respectively. Note that the findings from the DF scheme also corroborate those from other TC observations where the average height of the maximum wind appears around $500 \mathrm{~m}$ (see Figs. 8 and 10 of Franklin et al. 2003). In terms of the radial wind, both numerical experiments replicate the constant radial wind near the surface (from 20 $\mathrm{m}$ to $60 \mathrm{~m}$ ), which violates the log-law pattern characteristic (constant slope) of well-mixed layers. Black (2012) proposed that the constant radial wind leads to higher than expected near-surface winds of Typhoon Megi. However, the MYNN scheme leads to a deeper inflow layer with 1000-m depth as compared to a more realistic $650-\mathrm{m}$ height of the DF scheme. Interestingly, the deepening of the maximum wind speed with MYNN coincides with that of the inflow layer $(z=1 \mathrm{~km})$ and strengthening of the upper PBL radial 
wind just above the $60-\mathrm{m}$ altitude. As mentioned by Montgomery et al. (2010) and Gopalakrishnan et al. (2013), the deeper the inflow, the weaker it becomes in the boundary layer. This is not necessarily the case in the present study. MYNN weakens the inflow over the surface but enhances it at the upper boundary layer. Further analysis is provided in the next section.

\subsection{Impacts of $C d 1.5$ and MYNN}

\section{a. Friction-induced structural change}

As mentioned in the methodology, the idea of the experiments is to introduce frictional force to the control run. Figure 4 illustrates the resulting change in Megi's low-level wind structures due to the impacts of Cd1.5 and MYNN during the initial stage of deepening $(t=12$ to $t=24 \mathrm{~h})$.

As shown in Fig. 4a, the mean tangential wind simulated by the Deardorff scheme (DF and Cd1.5) is maximal at $0.773-\mathrm{km}$ level, much shallower than that of MYNN at $1.19-\mathrm{km}$ height. The difference on the vertical profiles of $v_{\phi}$ among the two schemes implies that the vertical momentum mixing of MYNN may be too strong for the 2-km mesh model. This notable difference in depth, as well as in width, is also illustrated at $t=12 \mathrm{~h}$ in Fig. $4 \mathrm{~b}$, where the maximum tangential wind $\left(v_{\phi, \max }\right)$ for Cd1.5 is lower in height $(z \sim 0.4 \mathrm{~km})$ and closer to the center (radius $\sim 30 \mathrm{~km})$ than the control run $(z \sim 0.5 \mathrm{~km}$; radius $\sim 60 \mathrm{~km})$. The MYNN case, in contrast to Cd1.5, reproduced a deeper $(z \sim 1 \mathrm{~km})$ and a larger radius of $v_{\phi, \text { max }}(\sim 90$ $\mathrm{km}$ radius). Furthermore, Fig. 4a shows that the average $v_{\phi}$ over the surface weakened after increasing $C d\left(v_{\phi}, \mathrm{Cd} 1.5<v_{\phi, \mathrm{DF}}\right)$. At the PBL $v_{\phi}$ is also found to be weaker for the MYNN case $\left(v_{\phi}\right.$, MYNN $<v_{\phi}$, DF $)$ brought about by its enhanced vertical mixing which leads to higher eddy viscous stress and momentum transport, as is discussed later. The reduced cyclonic winds due to friction generates stronger radial inflows (Figs. 4c, d) near the surface for Cd1.5 $\left(\left|-v_{r}, \mathrm{Cd} 1.5\right|>\left|-v_{r}, \mathrm{DF}\right|\right)$ and upper PBL for MYNN ( $\mid-v_{r}$, MYNN $|>|-v_{r}$, DF $\left.\mid\right)$. That is, both Cd1.5 and MYNN disrupt the gradient wind balance more than the DF run, which causes a stronger friction-induced radial inflow. In this paper, we refer the friction-induced weaker $v_{\phi}$ and stronger $\left(-v_{\mathrm{r}}\right)$ as "subgradient tangential wind" and "agradient inflow", respectively.

Shown in Fig. 5 is the resulting structure of Typhoon Megi in terms of the radius of maximum wind (RMW) and radius of the outermost closed isobars (ROCI with $17 \mathrm{~m} \mathrm{~s}^{-1}$ gale winds). Our results indicate that increasing the surface drag leads to the reduction of the maximum wind $\left(v_{\phi, \max } \sim v_{\max }\right)$, which enhances low-level convergence near the surface and toward the center of the storm, and subsequently, shrinks the eyewall (Fig. 5a). Although MYNN also spins down $v_{\phi}$ at the upper boundary level which enhances the inflow far from the center, it also intensifies the cyclonic wind near the surface which suppresses the radial flow of air towards the center. The result, as shown in Fig. 5a, is a larger radius of the maximum wind during the early stage ( $t=0$ to $t$ $=24 \mathrm{~h}$ ) of Typhoon Megi, as well as from its rapid intensification stage until before reaching maximum intensity $(t=48$ to $t=94 \mathrm{~h}$ ). The wind circulation in terms of ROCI also shows an inverse trend with Cd1.5 and increasing trend with MYNN (Fig. 5b). This further implies that Cd1.5 reduces the size of the circulation while MYNN enlarges it.

\section{b. KE balance during intensification}

As discussed in the literature, TCs are energized by the released latent heat because of the condensation of moist convection within the eyewall and rainbands (Nolan et al. 2007; Sawada and Iwasaki 2010). Fraction of this latent heat energy is transformed into the available potential energy (APE) and the $K E$ of the system. $K E$ conversion increases in the boundary layer near the center due to strong inflow down the pressure gradient. A seminal paper by Kurihara (1975) explains that an increase in $K E$ generation is associated with a positive feedback process which builds up a warm moist core, accelerates the secondary circulation, and intensifies moist convection. The result is a net outflow of mass from the TC center and a drop of the central pressure. Several other researches had been conducted to discuss the energetics of TCs (Palmen and Reihl 1957; Malkus and Reihl 1960; Tuleya and Kurihara 1975; Emanuel 1997, 2004, 2007; Shen 2004; Nolan et al. 2007; Sawada and Iwasaki 2007; Kwon et al. 2008; Maclay et al. 2008; Wang and Xu 2010; Miyamoto and Takemi 2013). Here, we study a simplified $K E$ definition by assuming an axisymmetric TC driven by the mean $\mathrm{KE}\left(K_{M}\right)$, given by

$$
K_{M}=\frac{1}{2} \rho\left(\bar{v}_{r}^{2}+\bar{v}_{\phi}^{2}+\bar{w}^{2}\right),
$$

where $\rho, \overline{v_{r}}, \overline{v_{\phi}}$, and $\bar{w}$ refer to air density, and mean radial, tangential, and vertical velocity, respectively. To better understand the $K_{M}$ budget of Typhoon Megi during intensification, the volume-integrated $K_{M}$ tendency (KET) of an axially symmetric TC is derived in cylindrical coordinates $(r, \phi, z)$ where $r, \phi$, and $z$ are the radial, azimuthal, and vertical compo- 

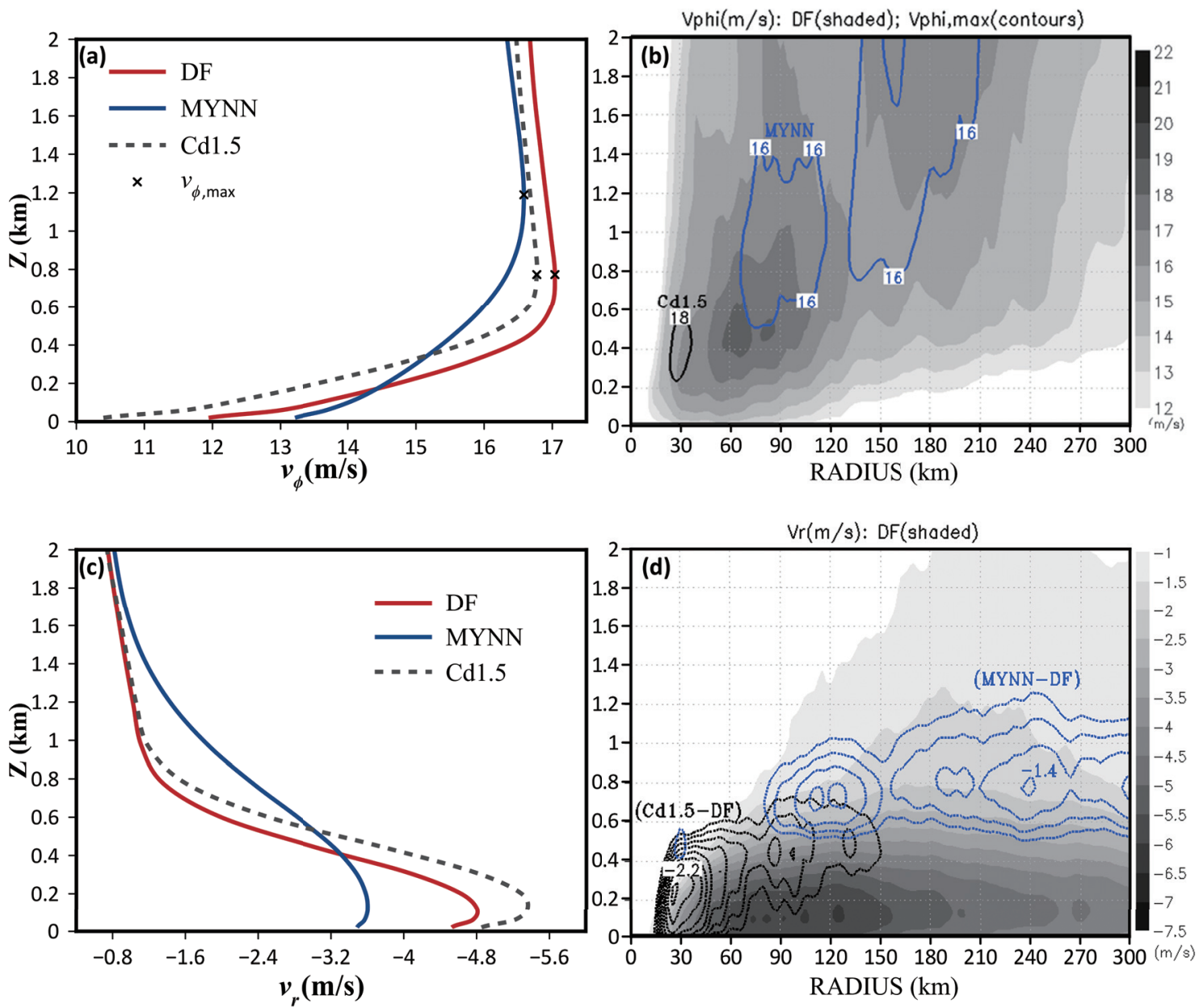

Fig. 4. Impacts of Cd1.5 and MYNN to the height-radial profile of the azimuthally averaged wind structures of Typhoon Megi. Panels on the first row illustrate the tangential wind: (a) averaged within $300 \mathrm{~km}$ radius and from $t=12$ to $t=24 \mathrm{~h}$; and (b) $v_{\phi}$ at $t=12 \mathrm{~h}$ of DF (shaded), $v_{\phi, \max }$ for Cd1.5 (black contour) and $v_{\phi, \max }$ for MYNN (blue contour). The second row shows the temporal mean of the radial inflow (inflow refers to negative values of $v_{r}$ ) from $t=12$ to $t=24 \mathrm{~h}$ : (c) averaged within $300 \mathrm{~km}$ radius; and (d) $v_{r}$ of DF (shaded) and the induced inflow ( $\left.\delta v_{r}\right)$ $\geq|-0.8| \mathrm{m} \mathrm{s}^{-1}$ by Cd1.5 (black contour) and MYNN (blue contour) with $0.2 \mathrm{~m} \mathrm{~s}^{-1}$ interval.

nents, respectively. As derived in APPENDIX, KET is defined by

$$
\begin{aligned}
& \left\langle\frac{\partial K_{M}}{\partial t}\right\rangle=\left\langle-\frac{1}{r} \frac{\partial}{\partial r} r \overline{v_{r}} K_{M}-\frac{\partial}{\partial z} \bar{w} K_{M}\right\rangle+\left\langle-\overline{v_{r}} \frac{\partial \bar{p}}{\partial r}\right\rangle \\
& \quad+\langle\rho,(\overline{\mathbf{v}} \cdot \overline{\mathbf{F}})\rangle+\left\langle-\left[\frac{1}{r} \frac{\partial}{\partial r} r v_{r}^{\prime} K_{M}+\frac{\partial}{\partial z} w^{\prime} K_{M}\right]\right. \\
& \left.\quad-\rho \frac{1}{r}\left[\overline{v_{\phi}} \frac{\overline{v_{\phi}^{\prime} v_{r}^{\prime}}}{r}-\overline{v_{r}} \overline{v_{\phi}^{\prime 2}}\right]\right\rangle,
\end{aligned}
$$

where $r, \frac{\partial \bar{p}}{\partial r}$, and $\overline{\mathbf{F}}$ represent the radius from the TC center, pressure gradient, and frictional force, respectively. The terms with a bar are azimuthally averaged, whereas those with a prime can be obtained by taking the deviation from the mean. The volume integral $\langle\ldots$. is defined by

$$
\langle A\rangle \equiv \int_{0}^{2 \pi} \int_{0}^{r} \int_{0}^{z} A r d z d r d \phi .
$$

The right hand side (rhs) of Eq. (4) denotes that KET is balanced by the energy flux (EF) across the boundary (first term), plus the dynamical energy conversion (EC) from the APE (second term), and energy loss (EL) due to friction (third term), with additional energy conversions due to eddies (KMKE; 

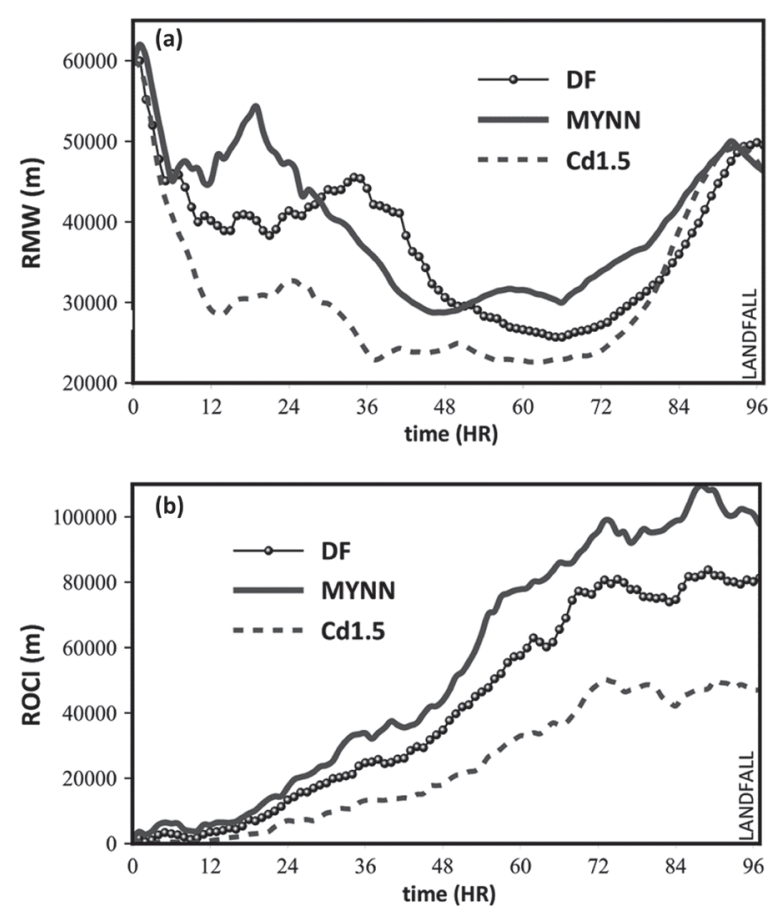

Fig. 5. Impact of Cd1.5 and MYNN on Typhoon Megi size in terms of: (a) radius of the maximum wind (RMW); and (b) radius of the outermost closed isobars (ROCI of $17 \mathrm{~m} \mathrm{~s}^{-1}$ gale winds).

forth term). Note that positive KMKE refers to the generation of $K_{M}$ from $K_{E}$ while negative values means EC from $K_{M}$ to $K_{E}$. The first, second, and fourth terms on the rhs of Eq. (4) can easily be calculated from the model output. KET is estimated directly from the rate of change of $K_{M}$. The energy loss is then calculated from the residue of Eq. (4).

The corresponding time-evolution of the volume-integrated energetics (KET, EC, EF, EL and KMKE) for the 2-km control run is plotted in Fig. 6 . All quantities are azimuthally averaged and vertically integrated from the second lowest level $(z=$ $20 \mathrm{~m})$ to the top level $(27.32 \mathrm{~km})$ within a $398-\mathrm{km}$ radius from the center of Typhoon Megi. Note that the maxima of EC and KET after $t=72 \mathrm{~h}$ represents the climax of rapid intensification (RI; see Fig. 7a), while the next peak (of EC, EL and KET) at $t=90$ $\mathrm{h}$ occurs just before reaching the maximum intensity. At $t=96$, KET drops to negative corresponding to the weakening of Typhoon Megi at landfall. Note that the tendency of $K_{M}$ to increase or decrease largely depends on the generation of $K_{M}$ from APE and dissipation due to surface friction. Here, the volume inte-

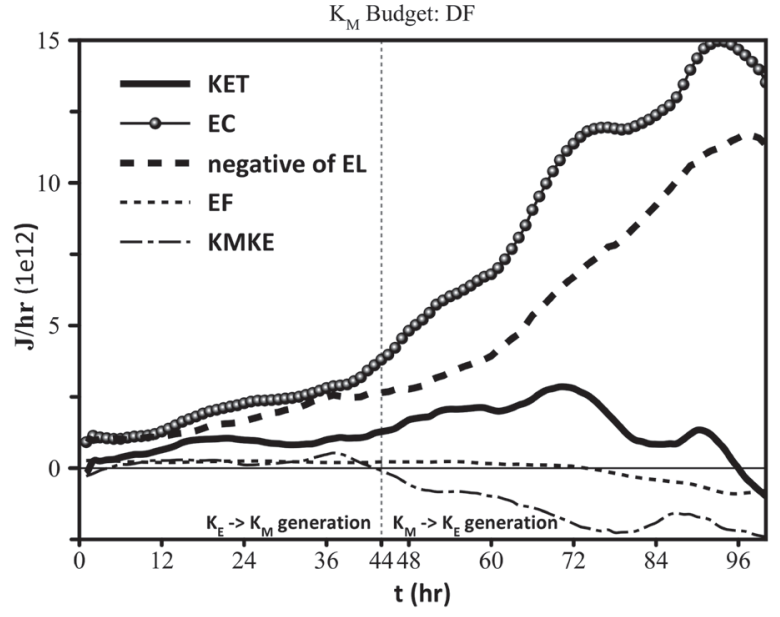

Fig. 6. Simulated volume-integrated mean $K E$ budget of the control experiment: KET, EC, $-\mathrm{EL}$, $\mathrm{EF}$ and KMKE. Note that at $t=44 \mathrm{~h}, \mathrm{KMKE}$ is negative which implies generation of $K_{E}$ from $K_{M}$. Here, the whole domain is volume-integrated: averaged azimuthally and from $z=0.02$ to $27.32 \mathrm{~km}$ within $398 \mathrm{~km}$ radius.

gral of the energy flux (EF) and KMKE are negligible as compared to EC and EL, especially during the early stage of Typhoon Megi. However, after $t=44 \mathrm{~h}$, KMKE negative contribution increases as it converts some $K_{M}$ to eddy $K E\left(K_{E}\right)$.

As shown in Fig. 7, increasing the surface drag and changing the DF scheme to MYNN demonstrate negative impacts on the kinetic energy budget of Typhoon Megi, associated with a weakening of the simulated intensity. That is, as Megi intensifies during EI (up to $t \sim 44 \mathrm{~h}$ ), the impacts of the experiments ( $\delta$ : $=\{\mathrm{Cd} 1.5, \mathrm{MYNN}\}$ minus DF) show that EL increases more than EC (Fig. 7c), leaving less energy for rapid intensification while dropping $\delta \mathrm{KET}$ to negative. Note in Figs. $7 \mathrm{a}$ and $7 \mathrm{~b}$ that before $t \sim 24 \mathrm{~h}, \mathrm{Cd} 1.5$ and MYNN started to slow down and weaken the TC while increasing both EL and EC. During RI, $\delta(-E L)$ continue to increase, while $\delta \mathrm{EC}$ falls to negative. At the later stage of intensification (from $t \sim 60 \mathrm{~h}$ ), both cases decrease EL and EC, resulting to a negative but increasing $\delta$ KET. Note that at this period, aside from the frictional effects of the experiments, other factors such as those involving KMKE should be considered. The contribution of KMKE on KET is interesting and needs further study. The present paper, however, is focused on the EI stage as the impact of friction, surface drag in particular, diminishes at high wind 

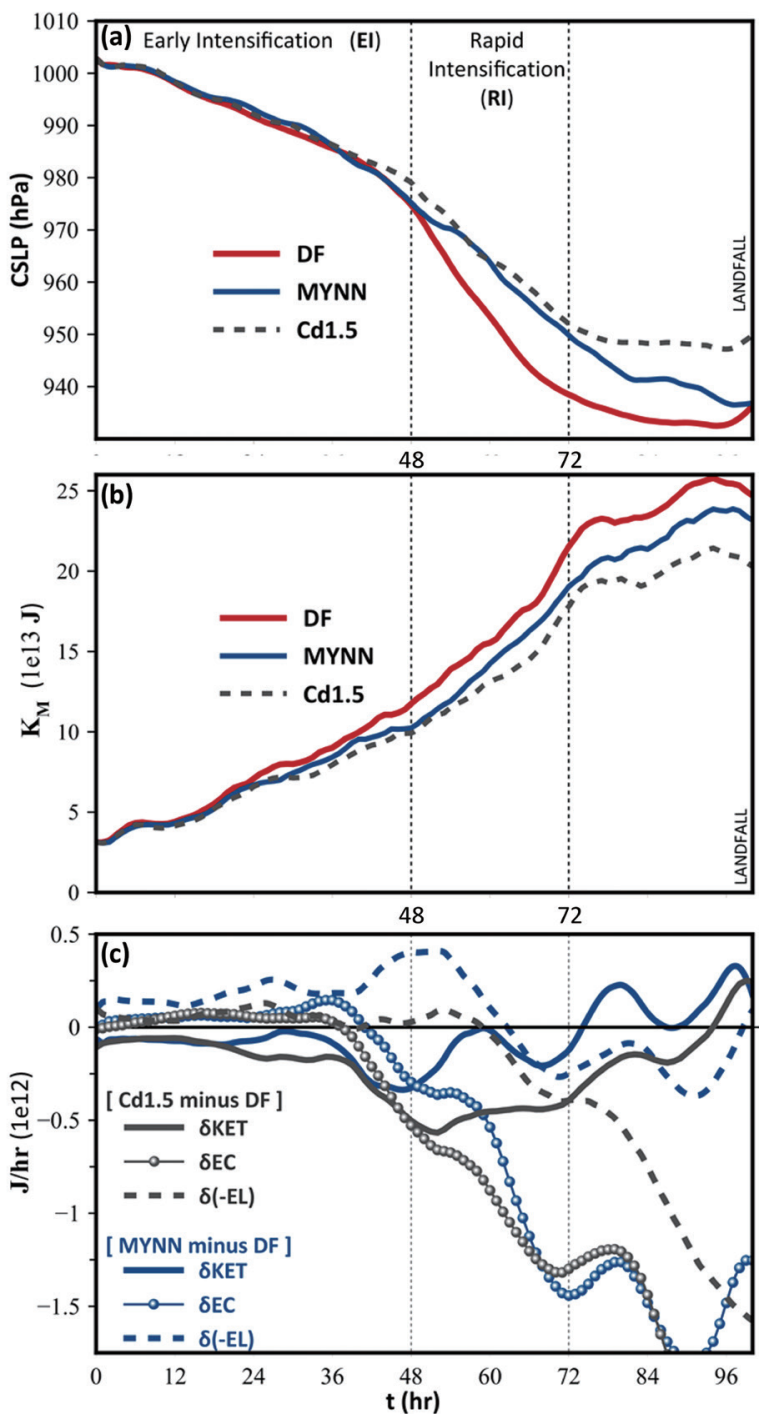

Fig. 7. Comparison of the experiments in terms of (a) central sea-level pressure (CSLP); (b) Volume-integrated $K_{M}$; and (c) impacts $(\delta$ : $=$ $\{\mathrm{Cd} 1.5, \mathrm{MYNN}\}$ minus DF) on KET, EC, and EL. The energy terms are volume-integrated (whole domain): averaged azimuthally and from $z=0.02$ to $27.32 \mathrm{~km}$ within $398 \mathrm{~km}$ radius. Note that the TC showed rapid intensification approximately from $t=48$ to $t=72 \mathrm{~h}$ and made landfall at $t=96 \mathrm{~h}$.

speed (Powell et al. 2003; Donelan et al. 2004; Zeng et al. 2010). In addition, the difference in the basic state characteristics at the free atmosphere for each case is negligible at the initial stage of Typhoon Megi. In the succeeding section, the impacts of the experi- ments are analyzed within the first $24 \mathrm{~h}$ of integration to discuss the dynamics that triggers the weaker intensity (see Figs. 7a, b) due to surface drag and MYNN.

\subsection{Discussion of the Results}

a. Impacts of the primary and secondary circulations on KET

In this section, the tendency of the kinetic energy is analyzed by examining the structural change introduced by the experiments on wind circulations during the EI period of Typhoon Megi. As shown in Appendix A of this paper, the kinetic energy equation leads us to energy gain and energy loss through the secondary and primary circulations, respectively (see Appendix A for the detailed derivation). Using the definition of TC as an axially symmetric system, the $\mathrm{EC}$ of an axisymmetric TC is described in terms of the mass streamfunction (MSF):

$$
\mathrm{EC} \approx\left\langle\left(-\overline{v_{r}}\right) \frac{\partial p}{\partial r}\right\rangle \doteqdot \frac{2 \pi}{\rho} \int_{0}^{r} \frac{\partial p}{\partial r} \operatorname{MSF}(r, z) d r .
$$

MSF depicts the secondary circulations (radial and vertical winds) of a TC as a result of friction, low-level convergence and buoyancy:

$$
\operatorname{MSF}(r, z)=-r \int_{z_{1}}^{z_{\text {top }}} \rho \overline{v_{r}} d z=\int_{0}^{r} \rho \bar{w} r d r .
$$

The EL due to frictional force $\boldsymbol{F}_{s}$, on the other hand, is expressed in terms of the absolute angular momentum, AAM. EL (see Appendix) is characterized by

$$
\begin{aligned}
\mathrm{EL} & \doteqdot-\iint \rho \mathbf{v} \cdot \boldsymbol{F}_{s} 2 \pi r d r d z \\
& \approx \int\left(\frac{\overline{v_{r}}}{r} \frac{\partial(\overline{\mathrm{AAM}})}{\partial r}+\frac{1}{\rho} \frac{\partial(-\tau)}{\partial z}\right) \overline{v_{\phi}} \Delta z \cdot 2 \pi r d r,
\end{aligned}
$$

where

$$
\begin{aligned}
& \left|\boldsymbol{F}_{s}\right| \approx-C_{d}{\overline{v_{\phi}}}^{2}, \\
& \mathrm{AAM} \equiv r v_{\phi}+\frac{1}{2} f r^{2}, \\
& \tau=-\rho \overline{w^{\prime} v_{\phi}^{\prime}} \approx \kappa_{m} \frac{\partial \overline{v_{\phi}}}{\partial z},
\end{aligned}
$$

and $\Delta z, \kappa_{m}, f, \tau$ and $\frac{\partial \overline{v_{\phi}}}{\partial z}$ represent the surface layer thickness, diffusivity momentum coefficient, Coriolis constant, eddy wind stress and vertical wind shear, respectively. Note from Eq. (10) that turbulence (eddies) transfers momentum downward. Furthermore, the bracketed terms on the rightmost side of 
Eq. (7) represent the EL due to frictional dissipation of AAM. The equation describing momentum loss can easily be derived from the conservation of AAM (see Appendix), and is given by

$$
\frac{\partial(\overline{\mathrm{AAM}})}{\partial t}+\overline{v_{r}} \frac{\partial(\overline{\mathrm{AAM}})}{\partial r}+\frac{r}{\rho} \frac{\partial(-\tau)}{\partial z}=r \boldsymbol{F}_{s} .
$$

Equation (11) is the tendency equation of AAM. At steady state, the AAM dissipation is balanced by the mean-radial and eddy-vertical transport of AAM; that is,

$$
\overline{v_{r}} \frac{\partial(\overline{\mathrm{AAM}})}{\partial r}+\frac{r}{\rho} \frac{\partial(-\tau)}{\partial z}=r \boldsymbol{F}_{s} .
$$

The impacts of Cd1.5 and MYNN on the secondary and primary circulations of Typhoon Megi with respect to the control run are illustrated in Figs. 8, 9 and 10, respectively. As mentioned in the previous section, the experiments introduced friction-induced structural change with opposite impacts on the vertical and radial wind profiles of Megi (see Figs. $4 \mathrm{~b}, \mathrm{~d})$. As proposed by Montgomery et al. (2010) the increase in $C d$ can disrupt the gradient-wind balance. The product is a stronger mass streamfunction ( $\delta \mathrm{MSF})$ with agradient inflow near the surface and eyewall (Fig. 8a). MYNN, on the other hand, induces a weaker surface radial wind but a stronger agradient inflow at the upper part of the PBL (contour lines in Fig. 8b). The suppressed inflow reduces the mass streamfunction at the lower boundary layer extending toward the eyewall. Nevertheless, the induced inflow at the upper PBL intensifies the MSF from the upper PBL upward. Taking the volume integral of the whole domain, both Cd1.5 and MYNN enhance the generation of kinetic energy as a result of the frictionally induced secondary flow. From the energetics view point, the inflow converts APE to kinetic energy that transports AAM and fuels water vapor to the eyewall of the typhoon.

As mentioned above, MYNN and Cd1.5 generate stronger MSF which transports high AAM towards the eyewall. The resulting AAM spatial distribution and budget because of the sensitivity experiments are depicted in Figs. 9 and 10, respectively. The AAM budget is determined from the volume-integrated AAM tendency equation:

$$
\left\langle\frac{\partial(\overline{\mathrm{AAM}})}{\partial t}\right\rangle+\left\langle\overline{v_{r}} \frac{\partial(\overline{\mathrm{AAM}})}{\partial r}\right\rangle+\left\langle\frac{r}{\rho} \frac{\partial(-\tau)}{\partial z}\right\rangle=\text { Mloss, }
$$

where the first term on the left-hand side represents
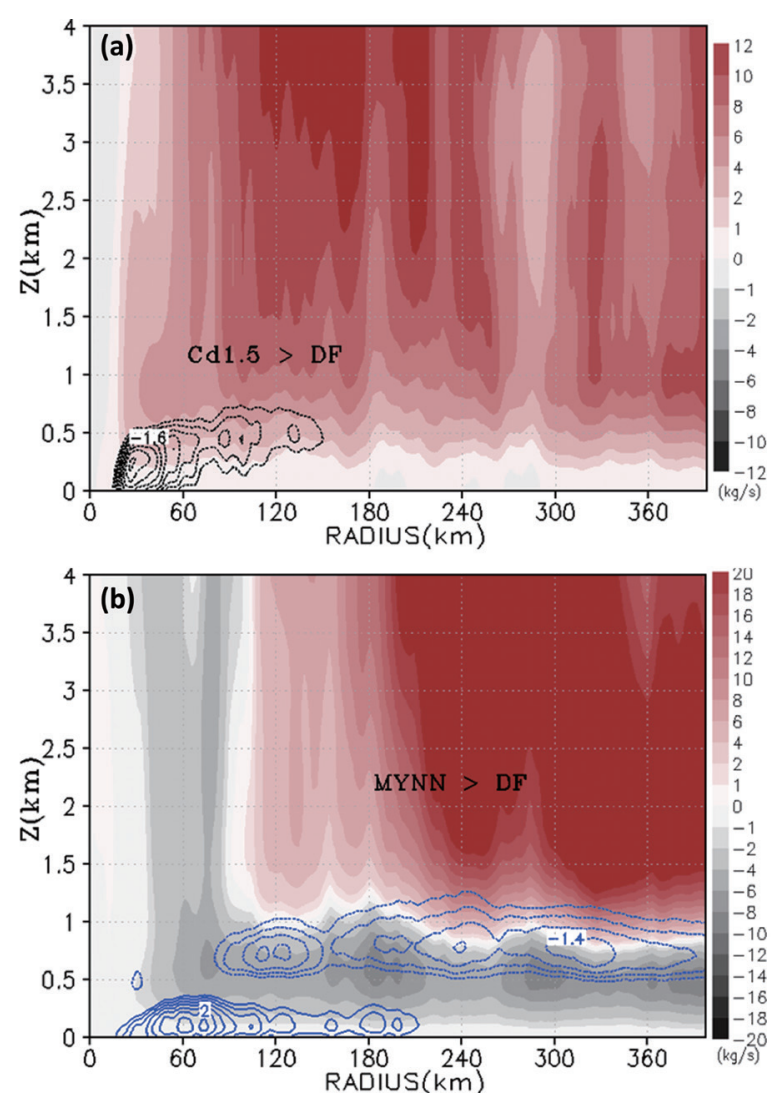

Fig. 8. Impacts of $\mathrm{Cd} 1.5$ and $\mathrm{MYNN}$ to the secondary circulation $\delta$ MSF $\left(1 \times 10^{7} \mathrm{~kg} \mathrm{~s}^{-1}\right)$. All plots were time-averaged from $t=0$ to $t=12 \mathrm{~h}$. The contour lines illustrate the impacts of $\mathrm{Cd} 1.5$ (black contours) and MYNN (blue contours) on radial wind with $\delta\left(v_{r}\right) \geq \pm 0.8 \mid \mathrm{m} \mathrm{s}^{-1}$ (interval $=0.2$ $\left.\mathrm{m} \mathrm{s}^{-1}\right)$. Negative $\delta\left(v_{r}\right)$ refers to induced inflow while positive value means weakened inflow.

the local tendency of AAM $(d M)$, Mloss refers to AAM dissipation, the second and third terms show the contributions of the radial advection $(\mathrm{Mr})$ and eddy-vertical transport $(\mathrm{Mz})$ of AAM, respectively. Here, we examine the AAM budget at the lower level (from the surface to $\sim 2 \mathrm{~km}$ height) of Typhoon Megi.

As shown in Fig. 9a, the local distribution of $\delta \mathrm{AAM}$ as a result of the Cd1.5 case is found to be negative near the surface but increasing toward the eyewall. This is because the friction-induced secondary circulation, which transports the momentum toward the center, increases with surface drag. As indicated in the momentum budget of Typhoon Megi (Fig. 10a), Mloss is strongly influenced by the enhanced radial inflow of AAM $(+\delta M r)$. 

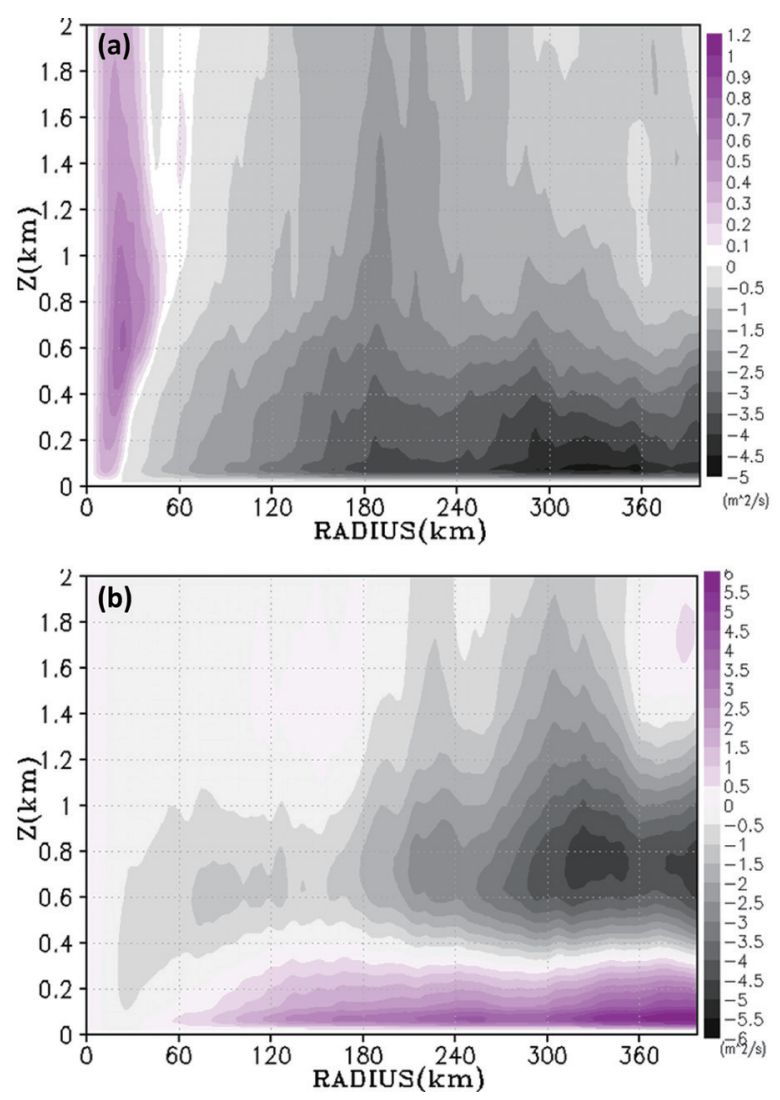

Fig. 9. Impacts of Cd1.5 and MYNN to the heightradial distribution of $\delta$ AAM $\left(1 \times 10^{5} \mathrm{~m}^{2} \mathrm{~s}^{-1}\right)$ : (a) Cd1.5 minus DF and (b) MYNN minus DF. All plots were time-averaged from $t=12$ to $t=$ $24 \mathrm{~h}$.

The impact on the vertical flux $(\delta M z)$, on the other hand, is relatively negligible due to the small change in the eddy stress $\tau$ (Fig. 11c). Thus, enhancing the surface momentum exchange coefficient $(\mathrm{Cd})$ dissi-

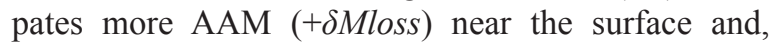
subsequently, increases the energy loss (see Eqs. 7 and 12). On the other hand, MYNN builds up $\tau$ (Fig. 11c) because of an enhanced vertical mixing, which then modulates the vertical AAM transport $(+\delta M z)$ as shown in Fig. 10b. The radial advection of AAM is also increased $(+\delta M r)$ due to the friction-induced inflow and intensified MSF in the upper PBL (Fig. $8 b)$. Hence, MYNN increases the AAM distribution near the surface in comparison with DF (Fig. 9b). Note, however, that the suppressed MSF in the lower PBL limits the radial flux of momentum in the lower layer near the eyewall. Nevertheless, the resulting frictional loss of AAM is increased ( $+\delta$ Mloss), and (a) Cd1.5 minus DF

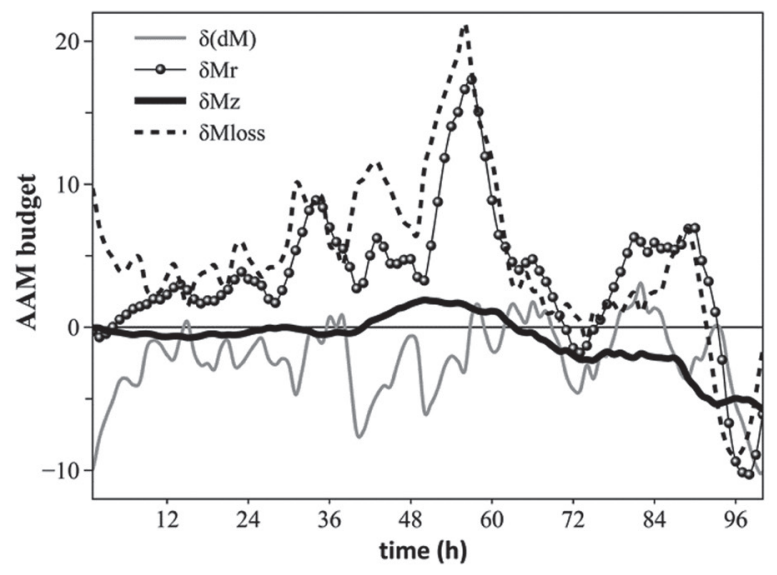

(b) MYNN minus DF

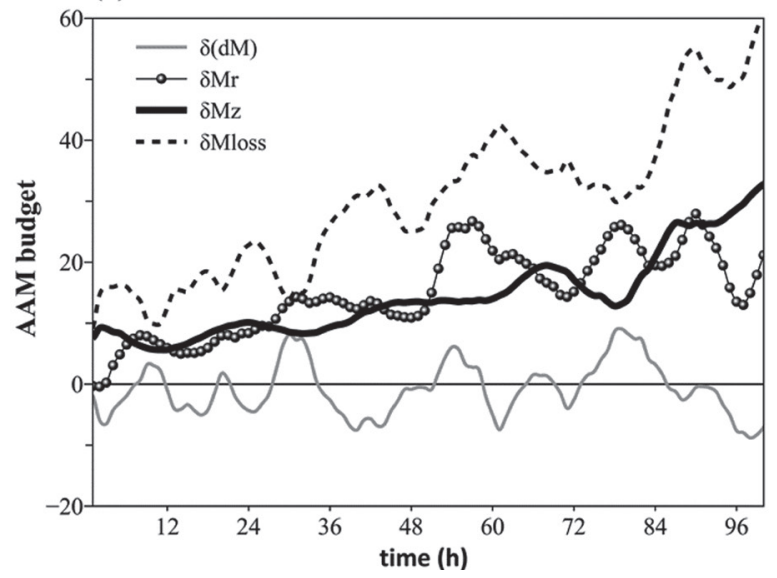

Fig. 10. Time series of the impacts of (a) Cd1.5 and (b) MYNN on the momentum budget of Typhoon Megi: $d M+M r+M z=$ Mloss. Mloss is calculated from the residue of the tendency equation. Here, the domain corresponding to Fig. 9 is volume-integrated (averaged azimuthally and from $z=0.02$ to $2 \mathrm{~km}$ within $398 \mathrm{~km}$ radius). Positive and negative curves imply an "increase" and a "decrease" of the term, respectively. The unit for the AAM budget is $1 \times 10^{12} \mathrm{~m}^{2} \mathrm{~s}^{-2} \mathrm{~m}^{3}$.

accordingly, more dissipation of kinetic energy. Note that the increased transport of AAM through the friction-induced secondary flow at the upper PBL also explains the enlarged wind circulation in the MYNN case (Sawada and Iwasaki 2010).

In summary, the energy loss due to AAM dissipation is greater in MYNN and Cd1.5 than that in the control case $\left(\mathrm{EL}_{\mathrm{MYNNb}}>\mathrm{EL}_{\mathrm{Cd} 1.5}>\mathrm{EL}_{\mathrm{CTL}}\right)$. The results also suggest that the increase in the frictional loss with Cd1.5 is primarily brought about by the 

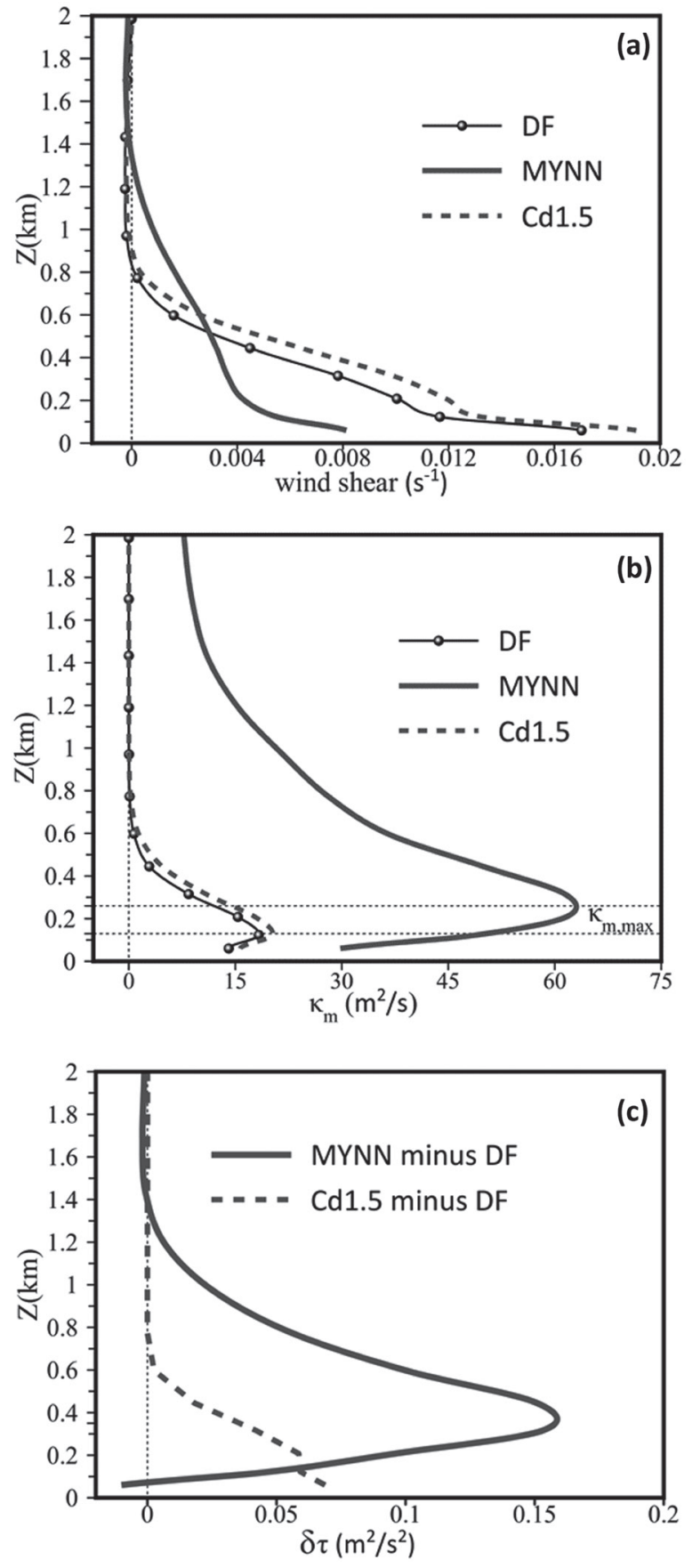

Fig. 11. Impacts of the sensitivity experiments on the AAM flux through the: (a) vertical wind shear; (b) eddy diffusion coefficient (the lines indicate the depth of max $\kappa_{m}$ ); and (c) tangential wind stress $(\delta \tau)$. The curves are azimuthally and spatio-temporally averaged within $398 \mathrm{~km}$ radius from $t=12$ to $t=24 \mathrm{~h}$. intensified radial AAM flux, while that with MYNN is mostly contributed by the induced inflow and enhanced eddy-vertical transport of AAM.

\section{b. Influence of eddy wind stress and vertical diffusion on KET}

To further understand the critical role of AAM flux on the energetics of Typhoon Megi, we examine the fundamental dynamics that influence vertical mixing forced by the eddy viscous stress. Note that $\tau$ is also referred to as vertical momentum flux in the downward direction. Following Eq. (9), we calculate the sensitivity (experiments minus DF) of the vertical profile of eddy diffusion coefficient $\left(\kappa_{m}\right)$ and wind shear $\left(\frac{\partial v_{\phi}}{\partial z}\right)$ during the early stage of intensification. The curves in Fig. 11 are averaged from $t=12$ to $t$ $=24 \mathrm{~h}$ within $398 \mathrm{~km}$ radius from the center of the typhoon. It is found that despite a weaker vertical wind shear in the MYNN case with respect to the control run and Cd1.5 (Fig. 11a), the resulting frictional loss is still larger due to a much stronger $\kappa_{m}$ (Fig. 11b), which translate to larger eddy stress (Fig. 11c) and downward momentum transport (Fig. 10b). Hence, the increased vertical flux of AAM, as shown in Fig. 10b, can be attributed to the enhanced momentum diffusion coefficient simulated by the MYNN scheme (Fig. 11b). Note that the impact of surface drag in terms of $\kappa_{m}$ is relatively insignificant, which explains the relatively smaller $\delta \tau$ of Cd1.5 as compared to that of the MYNN scheme.

In agreement with Kanada et al. (2012) and Gopalakrishnan et al. (2013), our findings with MYNN also imply that a larger and deeper diffusion modulates the transport of AAM in the boundary layer $(+\delta M z)$ as it induced gradients between the surface layer and the PBL. However, unlike Gopalakrishnan et al. (2013), the increased $\kappa_{m}$ in the present study is found to build up wind stress that leads to gradient-wind imbalance, inducing a stronger inflow in the upper PBL, and subsequently, more energy conversion. It is noteworthy to emphasize that the imbalance triggered by larger wind stress for the case of MYNN and Cd1.5 corroborates the findings of Smith and Vogl (2008) and Montgomery et al. (2010). However, the resulting maximum intensity is still weaker, which seems to contradict Montgomery et al. (2010), particularly for the case of the increased surface drag. The result from Cd1.5 is very interesting since it represents that of a realistic case. Moreover, in the idealized experiments of Montgomery et al. (2010), the intensity increases with increasing surface drag but with a threshold 
value of $\sim 1.3 \times 10^{-2}$ from where the intensity starts to decrease with $C d$. The findings from $\mathrm{Cd} 1.5$ regarding the impact of gradient wind imbalance still correspond with Montgomery et al. (2010) since the momentum exchange coefficient for the $\mathrm{Cd} 1.5$ case is $C_{m}=1.5 \times 10^{-1}$ (see Section 2.3), which is far beyond the critical value. Here, we attribute the weakening of Typhoon Megi to the negative impact of surface drag on the kinetic energy tendency in which the frictional energy dissipation offset the increase in energy conversion.

\section{Summary and conclusions}

Using a full-physics nonhydrostatic model with Deardorff PBL parameterization, Typhoon Megi is studied as it intensifies over the ocean. Here, the simulated TC is diagnosed by artificially introducing frictional perturbations, that is: (i) increase the surface friction with $C d(\mathrm{Cd} 1.5)$; and (ii) enhance the eddy viscous stress by changing the PBL scheme to MYNN Level 3. Similar to Bryan et al. (2013) and Kanada et al. (2012), we found that the control run calculates higher maximum intensity than $\mathrm{Cd} 1.5$ and MYYN. In reference to the ITOP/TCS10 data (Black 2012) and other TC observations (Franklin 2003), the DF scheme simulates more accurate boundary layer structures (shallower maximum tangential winds and lower inflow layer) than the MYNN scheme. To further understand the simulated intensity, the present paper utilizes the definition of volume-integrated KET as a sum of energy conversions (APE to $K_{M}$; and conversions between $K_{M}$ and $K_{E}$ ), energy loss and energy advection. Here, the kinetic energy tendency of Typhoon Megi is volume integrated: azimuthally, vertically $(z=0.02$ to $27.32 \mathrm{~km})$ and radially $(398 \mathrm{~km}$ radius from the TC center). The resulting KET shows that energy gain (APE to $K_{M}$ ) is balanced by energy loss during the first 2 days of integration. The experiments demonstrate substantial impacts on the energetics of Typhoon Megi in relation to the frictional perturbations introduced by $\mathrm{Cd} 1.5$ and MYNN on low-level wind structures. Changes in $v_{r}$, and hence in mass streamfunction, affect the dynamical energy conversion; while variations in $v_{\phi}$, subsequently in momentum flux and dissipation, affect energy loss.

Our findings indicate that (i) increasing $C d$ weakens the low-level tangential wind, which induces imbalance within the boundary layer stronger than the DF case. The imbalance enhances the inflow near the surface and toward the eyewall which then shrinks the eyewall (RMW) and circulation (ROCI) of the TC. (ii) On the contrary, increasing the vertical mixing with MYNN scheme enhances the shear stress which then reduces the upper-layer tangential wind and generates imbalance in the upper part of the PBL. The agradient inflow is enhanced in the upper boundary layer, far from the eyewall but weakened near the surface. The perturbation elevates the height and widens the radius of the maximum tangential wind, which leads to an increased TC size (RMW and ROCI).

The impact of the friction-induced structural change on the energetics of Typhoon Megi is dual, i.e., while it enhances the dynamical EC, it also amplifies EL. Our findings suggest that an induced inflow due to gradient-wind imbalance plays a critical role in strengthening the secondary circulation and thus enhancing the MSF. From the $K E$ equation, the dynamical $K_{M}$ conversion increases due to strong MSF down the pressure gradient. That is, both perturbations increase the $K_{M}$ gains by inducing a stronger inflow near the surface $(\mathrm{Cd} 1.5)$ and the upper PBL (MYNN). However, the enhanced EC is offset by the increase in EL which results in a negative energy tendency, and subsequently, spins down the circulation.

In this study, the weakening of Typhoon Megi as a result of larger EL is mainly influenced by changes in the primary circulation and transport of AAM across the TC. It is important to note that the mechanism for EL in Cd1.5 is significantly different from that in MYNN due to their different impacts on wind structures and momentum budget. Cd1.5 reduces the tangential wind at the lower level as it enhances the radial inflow. As a result, the radial advections of AAM toward the eyewall is increased, which leads to more momentum dissipation, and accordingly, $K_{M}$. On the contrary, the MYNN case enhances the tangential winds near the surface. It also amplifies the radial and eddy-downward momentum transport as it modulates the diffusivity coefficient. The result is a greater frictional dissipation of AAM, and consequently, $K_{M}$.

There are several established theories and idealized studies that explain intensity change in relation to frictional perturbations. Here, we present a realistic case and show that the friction-induced structural change during energy generation and dissipation reveals triggering dynamics (e.g., size expansion and contraction) of intensity change. It is apparent from our results that the weakening or intensification of Megi during its early development stage can be explained by the balance between dynamical EC and EL. To sum up, increasing the surface friction with $C d$ yields a weaker 
small TC whereas enhancing the vertical mixing with MYNN simulates a weaker large TC. The universality of our findings, however, has to be established and strengthened. In the future, we intend to extend our current work by improving the accuracy of the model with the PBL scheme and conducting further sensitivity analysis to other typhoons.

\section{Acknowledgments}

The authors would like to thank the MRI and JMA for the permission to use their data and the Nonhydrostatic Model. The authors also deeply acknowledge the technical assistance from members of the Atmospheric Science Laboratory and the supercomputing system provided by the Cyberscience Center in Tohoku University. We also thank two anonymous reviewers for their constructive comments that helped improve this manuscript.

\section{APPENDIX: The energetics formulation}

In this section, the KET is derived in cylindrical coordinates $(r, \phi, z)$ and under hydrostatic approximation. The $K E$ is first defined by:

$$
K E=\frac{1}{2} \rho\left(v_{r}^{2}+v_{\phi}^{2}+w^{2}\right),
$$

where $\rho, v_{r}, v_{\phi}$ and $w$ refer to air density, radial, tangential and vertical velocity, respectively. Equation (a1) is divided into an axisymmetric mean part, referred to as mean kinetic energy $K_{M}$, and an asymmetric term, referred to as eddy kinetic energy $K_{E}$. To separate $K_{M}$ and $K_{E}$, the velocity components are defined as:

$$
\begin{aligned}
& v_{\phi}=\overline{v_{\phi}}+v_{\phi}^{\prime}, \\
& v_{r}=\overline{v_{r}}+v_{r}^{\prime},
\end{aligned}
$$

and

$$
w=\bar{w}+w^{\prime},
$$

where a bar means an azimuthal average and a prime is the asymmetric term which is deviation from the mean. Using Eq. (a2), $K E$ can be divided into $K_{M}$ plus $K_{E}$ where

$$
K_{M}=\frac{1}{2} \rho\left({\overline{v_{r}}}^{2}+{\overline{v_{\phi}}}^{2}+\bar{w}^{2}\right),
$$

and

$$
K_{E}=\frac{1}{2} \rho\left(v_{r}^{\prime 2}+v_{\phi}^{\prime 2}+w^{\prime 2}\right) .
$$

In the present paper, the contribution of $K_{M}$ is consid- ered as the main driver of a TC such that our derivations will focus on the budget of the $K_{M}$ tendency. To solve for the kinetic energy equation, the momentum equations are derived in terms of Eq. (a2):

$$
\frac{d \overline{v_{r}}}{d t}=\frac{{\overline{v_{\phi}}}^{2}}{r}+\frac{\overline{v_{\phi}^{\prime 2}}}{r}+f \overline{v_{\phi}}-\frac{1}{\rho} \frac{\partial \bar{p}}{\partial r}+\bar{F} r
$$

and

$$
\frac{d \overline{v_{\phi}}}{d t}=-\frac{\overline{v_{\phi}} \overline{v_{r}}}{r}-\frac{\overline{v_{\phi}^{\prime} v_{r}^{\prime}}}{r}-f \overline{v_{r}}+\overline{F_{\phi}} .
$$

where $r, f, p$, and $F$ refer to the distance from the TC center, Coriolis constant, pressure and frictional force, respectively. The tendency equation for can be obtained by utilizing Eqs. (a5) and (a6). Using the continuity equation

$$
\frac{d K_{M}}{d t}+K_{M} \nabla \cdot \mathbf{v}=\frac{\partial K_{M}}{\partial t}+\nabla \cdot\left(K_{M} \mathbf{v}\right),
$$

to an axially symmetric TC and noting that $\nabla \cdot \mathbf{v}=0$, the $K E$ equation can be written as

$$
\begin{aligned}
& \frac{\partial K_{M}}{\partial t}=\left\{-\frac{1}{r} \frac{\partial}{\partial r} r \overline{v_{r}} K_{M}-\frac{\partial}{\partial z} \bar{w} K_{M}\right\}+\left\{-\overline{v_{r}} \frac{\partial \bar{p}}{\partial r}\right\} \\
& +\rho(\overline{\mathbf{v}} \cdot \overline{\mathbf{F}})+\left\{-\left[\frac{1}{r} \frac{\partial}{\partial r} r v_{r}^{\prime} K_{M}+\frac{\partial}{\partial z} w^{\prime} K_{M}\right]\right. \\
& \left.-\rho \frac{1}{r}\left[\overline{v_{\phi}} \frac{\overline{v_{\phi}^{\prime} v_{r}^{\prime}}}{r}-\overline{v_{r}} \overline{{v_{\phi}^{\prime}}^{2}}\right]\right\} .
\end{aligned}
$$

Here, we calculate the $K_{M}$ budget by taking the volume integral of Eq. (a7):

$$
\begin{aligned}
& \left\langle\frac{\partial K_{M}}{\partial t}\right\rangle=\left\langle-\frac{1}{r} \frac{\partial}{\partial r} r \overline{v_{r}} K_{M}-\frac{\partial}{\partial z} \bar{w} K_{M}\right\rangle+\left\langle-\overline{v_{r}} \frac{\partial \bar{p}}{\partial r}\right\rangle \\
& +\langle\rho(\overline{\mathbf{v}} \cdot \overline{\mathbf{F}})\rangle+\left\langle-\left[\frac{1}{r} \frac{\partial}{\partial r} r v_{r}^{\prime} K_{M}+\frac{\partial}{\partial z} w^{\prime} K_{M}\right]\right. \\
& \left.\quad-\rho \frac{1}{r}\left[\overline{v_{\phi}} \frac{\overline{v_{\phi}^{\prime} v_{r}^{\prime}}}{r}-\overline{v_{r}} \overline{v_{\phi}^{\prime}}\right]\right\rangle,
\end{aligned}
$$

where $\langle\ldots\rangle$ means

$$
\langle A\rangle \equiv \int_{0}^{2 \pi} \int_{r_{1}}^{r_{2}} \int_{z_{1}}^{z_{2}} A r d z d r d \phi .
$$

Eq. (a8) describes a volume-integrated mean KET of axially symmetric TC balanced by the energy flux (EF) across the boundary (first term on the right hand side), energy conversion from available poten- 
tial energy (EC; second term), energy loss (EL) due to friction (third term), and energy contribution from the eddies (energy conversions: $K_{E}$ to $K_{M}$ (+KMKE) or $K_{M}$ to $K_{E}$ (-KMKE); forth term) that is,

$$
\mathrm{KET}=\mathrm{EF}+\mathrm{EC}+\mathrm{EL}+\mathrm{KMKE}
$$

Mathematically, one can examine the primary and secondary circulations of a TC by defining EC and EL, respectively. The converted energy of an axisymmetric TC from APE is given by

$$
E C \approx\left\langle-\overline{v_{r}} \frac{\partial}{\partial r}\right\rangle \doteqdot \frac{2 \pi}{\rho} \int_{0}^{r} \frac{\partial p}{\partial r} \operatorname{MSF}(r, z) d r
$$

where MSF is the mass streamfunction described as

$$
\operatorname{MSF}(r, z)=\rho r \int_{z_{1}}^{z_{\text {top }}}-\overline{v_{r}} d z=\rho \int_{0}^{r} \bar{w} r d r .
$$

The EL due to surface frictional force $\left(\boldsymbol{F}_{s}\right)$, on the other hand, is characterized by

$$
\begin{aligned}
\mathrm{EL} & =\langle\rho \mathbf{v} \cdot \mathbf{F}\rangle \doteqdot-\iint \rho \mathbf{v} \cdot \boldsymbol{F}_{S} 2 \pi r d r d z \\
& \approx \int-C_{d}{\overline{v_{\phi}}}^{2} V \quad \Delta z \cdot 2 \pi r d r \approx \int-C_{d}{\overline{v_{\phi}}}^{3} \Delta z \cdot 2 \pi r d r,
\end{aligned}
$$

where

$$
\left|\boldsymbol{F}_{s}\right| \approx-C_{d}{\overline{v_{\phi}}}^{2},
$$

where $\left|\boldsymbol{F}_{s}\right|, V$ and $\Delta z$ represent the magnitude of surface friction, wind speed, and surface layer thickness, respectively. Here, we assume $w, v_{r} \ll v_{\phi}$; hence, $V{\overline{v_{\phi}}}^{2} \sim{\overline{v_{\phi}}}^{3}$.

Now consider the AAM against the center of an axisymmetric cyclone as defined by

$$
\mathrm{AAM} \equiv r v_{\phi}+\frac{1}{2} f r^{2}
$$

The conservation principle of angular momentum can easily be derived from the tangential momentum equation using Eq. (a13), that is

$$
\frac{d(\mathrm{AAM})}{d t}=r F_{\phi} \text {. }
$$

Using the continuity equation

$$
\nabla \cdot[\rho \mathbf{v} \overline{\mathrm{AAM}}]=[\nabla \overline{\mathrm{AAM}} \cdot \rho \mathbf{v}],
$$

and taking the azimuthal average of Eq. (a14) leads to

$$
\begin{aligned}
& \frac{\partial(\overline{\mathrm{AAM}})}{\partial t}+v_{r} \frac{\partial(\overline{\mathrm{AAM}})}{\partial r}+\frac{1}{\rho} \frac{\partial}{\partial z} \overline{\rho(\mathrm{AAM}) w} \\
& =-r C_{d}{\overline{v_{\phi}}}^{2} .
\end{aligned}
$$

After substituting Eq. (a2) into Eqs. (a13) and (a15), and noting that there is no mean advection near the surface, the conservation of angular momentum can now be rewritten to

$$
\begin{aligned}
& \frac{\partial(\overline{\mathrm{AAM}})}{\partial t}+\overline{v_{r}} \frac{\partial(\overline{\mathrm{AAM}})}{\partial r}+\frac{r}{\rho} \frac{\partial}{\partial z} \overline{\rho v_{\phi}^{\prime} w^{\prime}} \\
& =-r C_{d}{\overline{v_{\phi}}}^{2} .
\end{aligned}
$$

or

$$
\frac{\partial(\overline{\mathrm{AAM}})}{\partial t}+\overline{v_{r}} \frac{\partial(\overline{\mathrm{AAM}})}{\partial r}+\frac{r}{\rho} \frac{\partial(-\tau)}{\partial z}=-r C_{d}{\overline{v_{\phi}}}^{2} .
$$

where $\tau$ represents the eddy shear stress

$$
\tau=-\overline{\rho w^{\prime} v_{\phi}^{\prime}} .
$$

Hence during steady state the frictional loss of the torque at the lowest level balances with the sum of radial advection and vertical eddy transport of momentum as follows;

$$
\overline{v_{r}} \frac{\partial(\overline{\mathrm{AAM}})}{\partial r}+\frac{r}{\rho} \frac{\partial(-\tau)}{\partial z}=-r C_{d}{\overline{v_{\phi}}}^{2},
$$

With the help of Eq. (a18), the integrand in the EL Eq. (a13) can now be rewritten as

$$
\begin{aligned}
\mathrm{EL} & \doteqdot \iint \rho \mathbf{v} \cdot \boldsymbol{F}_{s} 2 \pi r d r d z \\
& \approx \int\left(\frac{\overline{v_{r}}}{r} \frac{\partial(\overline{\mathrm{AAM}})}{\partial r}+\frac{1}{\rho} \frac{\partial(-\tau)}{\partial z}\right) \overline{v_{\phi}} \Delta z \cdot 2 \pi r d r .
\end{aligned}
$$

As implied in the above equation, the energy loss of an axially symmetric TC is crossly related to the inward (mean-radial) and eddy-downward angular absolute momentum transport.

\section{References}

Beljaars, A. C. M., and A. A. M. Holtslag, 1991: Flux parameterization over land surfaces for atmospheric models. J. Appl. Meteor., 30, 327-341.

Bell, M. M., M. T. Montgomery, and K. A. Emanuel, 2012: Air-sea enthalpy and momentum exchange at major hurricane wind speeds observed during CBLAST. $J$. Atmos. Sci., 69, 3197-3222.

Black, P. G., 2012: Tropical cyclone unusual intensity and structure change in the western North Pacific observed by reconnaissance aircraft during TPARC/TCS08 and ITOP/TCS10. Tropical Cyclone Research and Review, 
1, 75-88.

Blackadar, A. K., 1962: The vertical distribution of wind and turbulent exchange in a neutral atmosphere. $J$. Geophys. Res., 67, 3095-3102.

Braun, S. A., and W.-K. Tao, 2000: Sensitivity of high-resolution simulations of Hurricane Bob (1991) to planetary boundary layer parameterizations. Mon. Wea. Rev., 128, 3941-3961.

Bryan, G. H., 2013: Comments on 'Sensitivity of tropicalcyclone models to the surface drag coefficient'. Quart. J. Roy. Meteor. Soc., 139, 1957-1960.

Charney, J. G., and A. Eliassen, 1964: On the growth of the hurricane depression. J. Atmos. Sci., 21, 68-75.

Deardorff, J. W., 1980: Stratocumulus-capped mixed layers derived from a three-dimensional model. Bound.-Layer Meteor, 18, 495-527.

Donelan, M. A., W. M. Drennan, and K. B. Katsaros, 1997: The air-sea momentum flux in conditions of wind sea and swell. J. Phys. Oceanogr., 27, 2087-2099.

Donelan, M. A., B. K. Haus, N. Reul, W. J. Plant, M. Stiassnie, H. C. Graber, O. B. Brown, and E. S. Saltzman, 2004: On the limiting aerodynamic roughness of the ocean in very strong winds. Geophys. Res. Lett., 31, L18306, doi:10.1029/2004GL019460.

Emanuel, K. A., 1986: An air-sea interaction theory for tropical cyclones. Part I: Steady-state maintenance. $J$. Atmos. Sci., 43, 585-604.

Emanuel, K. A., 1995: Sensitivity of tropical cyclones to surface exchange coefficients and a revised steady-state model incorporating eye dynamics. J. Atmos. Sci., 52, 3969-3976.

Emanuel, K. A., 1997: Some aspects of hurricane inner-core dynamics and energetics. J. Atmos. Sci., 54, 1014 1026.

Emanuel, K. A., 2004: Tropical cyclone energetics and structure. Atmospheric Turbulence and Mesoscale Meteorology. Fedorovich, E., R. Rotunno, and B. Stevens (eds.), Cambridge University Press, 280 pp.

Emanuel, K. A., 2007: Environmental factors affecting tropical cyclone power dissipation. J. Climate, 20, 54975509.

Fang, J., J. P. Tang, and R. S. Wu, 2009: The effect of surface friction on the development of tropical cyclones. $A d v$. Atmos. Sci., 26, 1146-1156.

Fierro, A. O., R. F. Rogers, F. D. Marks, and D. S. Nolan, 2009: Impact of cloud resolving horizontal grid spacing on simulated tropical cyclone structure with emphasis on microphysics and kinematic fields. Mon. Wea. Rev., 137, 3717-3743.

Franklin, J. L., M. L. Black, and K. Valde, 2003: GPS dropwindsonde wind profiles in hurricanes and their operational implications. Wea. Forecasting, 18, 32-44.

Gentry, M. S., and G. M. Lackmann, 2010: Sensitivity of simulated tropical cyclone structure and intensity to horizontal resolution. Mon. Wea. Rev., 138, 688-704.

Gerard, L. 2007: An integrated package for subgrid convec- tion, clouds and precipitation compatible with mesogamma scales. Quart. J. Roy. Meteor. Soc., 133, 711-730.

Gopalakrishnan, S. G., F. Marks, J. Zhang, X. Zhang, J.-W. Bao, and V. Tallapragadet, 2013: A study of the impacts of vertical diffusion on the structure and intensity of the tropical cyclones using the high-resolution HWRF system. J. Atmos. Sci., 70, 524-541.

Ikawa, M., and K. Saito, 1991: Description of a nonhydrostatic model developed at the Forecast Research Department of the MRI. Technical Reports of the Meteorological Research Institute, 28, 238 pp.

Japan Meteorological Agency, 2013: Outline of the operational numerical weather prediction at the Japan Meteorological Agency. Appendix to WMO Technical Progress Report on the Global Data- Processing and Forecasting System and Numerical Weather Prediction (NWP) Research, Japan Meteorological Agency.

Kain, J. S., and J. M. Fritsch, 1993: Convective parameterization for mesoscale models: The Kain-Fritsch scheme. The representation of cumulus convection in numerical models. Meteor. Monogr., 24, 165-170.

Kanada, S., A. Wada, M. Nakano, and T. Kato, 2012: Effect of planetary boundary layer schemes on the development of intense tropical cyclones using a cloud-resolving model. J. Geophys. Res., 117, D03107, doi: 10.1029/2011JD016582.

Kurihara, Y., 1975: Budget analysis of a tropical cyclone simulated in an axisymmetric numerical model. $J$. Atmos. Sci., 32, 25-59.

Kurihara, Y., T. Sakurai, and T. Kuragano, 2006: Global daily sea surface temperature analysis using data from satellite microwave radiometer, satellite infrared radiometer and in-situ observations. Weather Bull., 73, s1-s18.

Kwon, Y. C., and W. M. Frank, 2008: Dynamic instabilities of simulated hurricane-like vortices and their impacts on the core structure of hurricanes. Part II: Moist experiments. J. Atmos. Sci., 65, 106-122.

Maclay, K. S., M. DeMaria, and T. H. Vonder Haar, 2008: Tropical cyclone inner-core kinetic energy evolution. Mon. Wea. Rev., 136, 4882-4898.

Malkus, J. S., and H. Riehl, 1960: On the dynamics and energy transformations in steady-state hurricanes. Tellus, 12, 1-20.

Miyamoto, Y., and T. Takemi, 2013: A transition mechanism for the spontaneous axisymmetric intensification of tropical cyclones. J. Atmos. Sci., 70, 112-129.

Montgomery, M. T., and R. K. Smith, 2011: Paradigms for tropical-cyclone intensification. Quart. J. Roy. Meteor. Soc., 137, 1-31.

Montgomery, M. T., R. K. Smith, and S. Nguyen, 2010: Sensitivity of tropical cyclone models to the surface drag coefficient. Quart. J. Roy. Meteor. Soc., 136, 1945-1953.

Murakami, M., 1990: Numerical modeling of dynamical and microphysical evolution of an isolated convective 
cloud: the 19 July 1981 CCOPE cloud. J. Meteor. Soc. Japan, 68, 107-128.

Nakanishi, M., 2001: Improvement of the Mellor-Yamada turbulence closure model based on large-eddy simulation data. Bound.-Layer Meteor, 99, 349-378.

Nakanishi, M., and H. Niino, 2004: An improved MellorYamada level 3 model with condensation physics: Its design and verification. Bound.-Layer Meteor, 112, $1-31$.

Nakanishi, M., and H. Niino, 2006: An improved MellorYamada level-3 model: Its numerical stability and application to a regional prediction of advection fog. Bound.-Layer Meteor., 119, 397-407.

Nolan, D. S., I.-J. Moon, and D. P. Stern, 2007: Tropical cyclone intensification from asymmetric convection: Energetics and efficiency. J. Atmos. Sci, 64, 33773405.

Nolan, D. S., J. A. Zhang, and D. P. Stern, 2009a: Evaluation of planetary boundary layer parameterizations in tropical cyclones by comparison of in situ observations and high-resolution simulations of Hurricane Isabel (2003). Part I: Initialization, maximum winds, and outer-core boundary layer. Mon. Wea. Rev., 137, 3651-3674.

Nolan, D. S., D. P. Stern, and J. A. Zhang, 2009b: Evaluation of planetary boundary layer parameterizations in tropical cyclones by comparison of in situ observations and high-resolution simulations of Hurricane Isabel (2003). Part II: Inner-core boundary layer and eyewall structure. Mon. Wea. Rev., 137, 3675-3698.

Onogi, K., J. Tsutsui, H. Koide, M. Sakamoto, S. Kobayashi, H. Hatsushika,T. Matsumoto, N. Yamazaki, H. Kamanori, K. Takahashi, S. Kadokura, K. Wada, K. Kato, R. Oyama, T. Ose, N. Mannoji, and R. Taira, 2007: The JRA-25 Reanalysis. J. Meteor. Soc. Japan, 85, 369-432.

Ooyama, K., 1964: A dynamical model for the study of tropical cyclone development. Geofis., 4, 187-198.

Palmen, E., and H. Riehl, 1957: Budget of angular momentum and energy in tropical cyclones. J. Meteor., 14, 150-159.

Powell, M. D., P. J. Vickery, and T. Reinhold, 2003: Reduced drag coefficient for high wind speeds in tropical cyclones. Nature, 422, 279-283.

Rosenthal, S. L., 1971: The response of a tropical cyclone model to variations in boundary layer parameters, initial conditions, lateral boundary conditions, and domain size. Mon. Wea. Rev., 99, 767-777.

Saito, K., T. Kato, H. Eito, and C. Muroi, 2001: Documentation of the Meteorological Research Institute/Numer- ical prediction Division unified nonhydrostatic model. Technical Reports of the Meteorological Research Institute, 42, $133 \mathrm{pp}$.

Saito, K., J. Ishida, K. Aranami, T. Hara, T. Segawa, M. Narita, and Y. Honda, 2007: Nonhydrostatic atmospheric models and operational development at JMA. J. Meteor. Soc. Japan, 85B, 271-304.

Sawada, M., and T. Iwasaki, 2007: Impacts of ice phase processes on tropical cyclone development. J. Meteor. Soc. Japan, 85, 479-494.

Sawada, M., and T. Iwasaki, 2010: Impacts of evaporation from raindrop on tropical cyclone. Part I: Evolution and axisymmetric structure. J. Atmos. Sci., 67, 71-83.

Shen, W., 2004: Hurricane potential intensity from an energetics point of view. Quart. J. Roy. Meteor. Soc., 130, 2629-2648.

Smith, R. K., and M. T. Montgomery, 2008: Balanced boundary layers used in hurricane models. Quart. J. Roy. Meteor. Soc., 134, 1385-1395.

Smith, R. K., and S. Vogl, 2008: A simple model of the hurricane boundary layer revisited. Quart. J. Roy. Meteor. Soc., 134, 337-351.

Smith, R. K., and G. L. Thomsen, 2010: Dependence of tropical-cyclone intensification on the boundary-layer representation in a numerical model. Quart. J. Roy. Meteor. Soc., 136, 1671-1685.

Smith, R. K., M. T. Montgomery, and N. V. Sang, 2009: Tropical cyclone spin-up revisited. Quart. J. Roy. Meteor. Soc., 135, 1321-1335.

Smith, R. K., M. T. Montgomery, and G. L. Thomsen, 2014: Sensitivity of tropical-cyclone models to the surface drag coefficient in different boundary-layer schemes. Quart. J. Roy. Meteor. Soc., 140, 792-804.

Tuleya, R. E., and Y. Kurihara, 1975: The energy and angular momentum budgets of a three-dimensional tropical cyclone model. J. Atmos. Sci., 32, 287-301.

Wang, Y., and J. Xu, 2010: Energy production, frictional dissipation, and maximum intensity of a numerically simulated tropical cyclone. J. Atmos. Sci., 67, 97-116.

Wang, H., and Y. Wang, 2014: A numerical study of Typhoon Megi (2010). Part I: Rapid intensification. Mon. Wea. Rev., 142, 29-48.

Wu, C., H. Cheng, Y. Wang, and K. Chou, 2009: A numerical investigation of the eyewall evolution in a landfalling typhoon. Mon. Wea. Rev., 137, 21-40.

Zeng, Z. H., Y. Q. Wang, Y. H. Duan, L. S. Chen, and Z. Q. Gao, 2010: On sea surface roughness parameterization and its effect on tropical cyclone structure and intensity. Adv. Atmos. Sci., 27, 337-355. 